\title{
Ammonia Elimination from Protonated Nucleobases and Related Synthetic Substrates
}

\author{
Ming Qian, Shuo Yang, Hong Wu, Papiya Majumdar, Nathan Leigh, \\ and Rainer Glaser \\ Department of Chemistry, University of Missouri-Columbia, Columbia, Missouri, USA
}

\begin{abstract}
The results are reported of mass-spectrometric studies of the nucleobases adenine $\mathbf{1 h}(\mathbf{1}, \mathrm{R}=$ $\mathrm{H})$, guanine $\mathbf{2} \mathbf{h}$, and cytosine $\mathbf{3 h}$. The protonated nucleobases are generated by electrospray ionization of adenosine $1 \mathrm{r}(1, \mathrm{R}=$ ribose), guanosine $2 \mathrm{r}$, and deoxycytidine $3 \mathrm{~d}(3, \mathrm{R}=$ deoxyribose) and their fragmentations were studied with tandem mass spectrometry. In contrast to previous EI-MS studies of the nucleobases, $\mathrm{NH}_{3}$ elimination does present a major path for the fragmentations of the ions $\left[1 \mathbf{h ~}+\mathrm{H}^{+},[2 \mathbf{h}+\mathrm{H}]^{+}\right.$, and $[3 \mathbf{h}+\mathrm{H}]^{+}$. The ion $[2 \mathbf{h}+$ $\left.\mathrm{H}-\mathrm{NH}_{3}\right]^{+}$also was generated from the acyclic precursor 5-cyanoamino-4-oxomethylenedihydroimidazole $13 \mathbf{h}$ and from the thioether derivative $14 \mathbf{h}$ of $\mathbf{2 h}\left(\mathrm{NH}_{2}\right.$ replaced by $\left.\mathrm{MeS}\right)$. The analyses of the modes of initial fragmentation is supported by density functional theoretical studies. Conjugate acids $\mathbf{1 5}-\mathbf{5 5}$ were studied to determine site preferences for the protonations of $\mathbf{1 h}, \mathbf{2 h}, 3 \mathrm{~h}, \mathbf{1 3 h}$, and $\mathbf{1 4 h}$. The proton affinity of the amino group hardly ever is the substrate's best protonation site, and possible mechanisms for $\mathrm{NH}_{3}$ elimination are discussed in which the amino group serves as the dissociative protonation site. The results provide semi-direct experimental evidence for the existence of the pyrimidine ring-opened cations that we had proposed on the basis of theoretical studies as intermediates in nitrosative nucleobase deamination. (J Am Soc Mass Spectrom 2007, 18, 2040-2057) (c) 2007 American Society for Mass Spectrometry
\end{abstract}

$\mathrm{N}$ itric oxide $(\mathrm{NO})$ and nitrous acid $\left(\mathrm{HNO}_{2}\right)$ cause DNA base deamination and interstrand crosslink formation $[1,2]$. This chemistry has been studied extensively because of the dietary and environmental exposure of humans to these substances [3-5]. Toxicological studies of deamination became more significant when it was recognized that endogenous nitric oxide $[6,7]$ causes nitrosation $[8,9]$, and that this process is accelerated by chronic inflammatory diseases [10, 11]. It has been known for a long time that deamination of adenine $\mathbf{1}$, guanine $\mathbf{2}$, and cytosine 3 (Scheme 1 ) results in the formation of hypoxanthine, xanthine, and uracil, respectively, and these products are thought to result from DNA base diazonium ions 4-6, respectively, by direct nucleophilic dediazoniation. The discovery of oxanine formation [12-14] in the nitrosative deamination of guanine challenged the generality and completeness of this mechanism. Theoretical studies revealed that unimolecular dediazoniation of guaninediazonium ion $\mathbf{5}$ is accompanied or immediately followed by pyrimidine ringopening $[15,16]$ and that cytosine-catalysis promotes the process $[17,18]$. The resulting 5-cyanoimino-4-oxomethylene-4,5-dihydroimidazole is a highly reactive intermediate and undergoes acid-catalyzed 1,4-addition via cyano- $N$ or imino- $N$ protonated 5-cyanoimino-4-oxomethylene-4,5-dihydroimidazoles, 9 and 10, respectively [19].

Address reprint requests to Professor R. Glaser, Department of Chemistry, University of Missouri-Columbia, 321 Chemistry Building, Columbia, Missouri 65211,USA.E-mail: GlaserR@missouri.edu
Labeling studies support this reaction mechanism for oxanine formation [20]. Moreover, we synthesized 5-cyanoamino-4-imidazolecarboxamide and studied its cyclization chemistry [21] and its proficiency for cross-link formation [22]. The unimolecular dediazoniation of the diazonium ions of adenine and cytosine can proceed without ring-opening but the cations $\mathbf{7}$ and $\mathbf{1 1}$ formed in this way are predicted to undergo facile ring-opening [23, $24]$ to ions 8 and $\mathbf{1 2}$, respectively (Scheme 1).

We reported the results of ab initio studies (MP2/6$\left.31 G^{*}\right)$ on the electronic structures of ions $\mathbf{9}$ and $\mathbf{1 0}$ and of their common conjugate base and solvent effects were considered by way of a continuum model [19]. The characteristic features of the ions persist in solution, but solvation does have a marked consequence on the site preference and the propensity for protonation. While cyano- $N$ protonation is preferred in gas phase, imino- $N$ protonation is preferred in polar condensed phase. While protonation is fast and exergonic in the gas phase, it is endergonic in polar condensed phase. It is an immediate consequence of these computational results that the direct observation of cations $\mathbf{9}$ and $\mathbf{1 0}$ is possible only in the gas phase.

In this context, it has been our aim to provide experimental evidence (1) for the existence of ions 8-10 and $\mathbf{1 2}$ and (2) for their formation by dediazoniation of the diazonium ions of the nucleobases $1 \mathrm{~h}, 2 \mathrm{~h}$, and $3 \mathrm{~h}$. With the present study, we address the first of these goals. The impetus for this study was provided by the realization that the ions produced by dediazoniation of the putative 


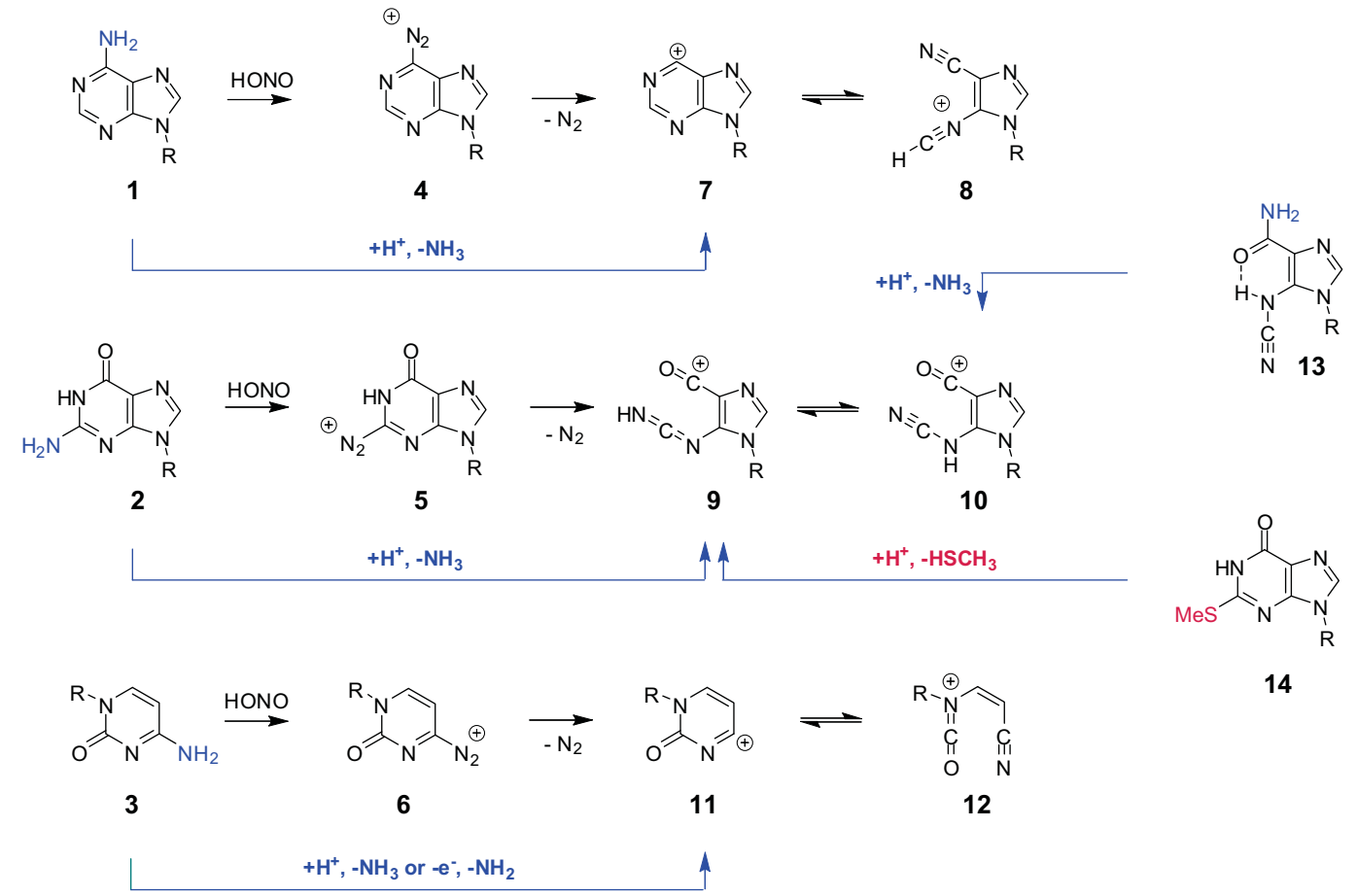

Scheme 1. Nucleoside and nucleobase deamination by nitrosation and by proton-catalyzed ammonia elimination.

nucleobase diazonium ions can be prepared in the gas phase via a sequence of protonation and ammonia elimination (Scheme 1). Hence, we have studied $\mathrm{NH}_{3}$ elimination form the conjugate acids of the nucleobases $\mathbf{~} \mathrm{h}-3 \mathrm{~h}$ and the models $13 \mathrm{~h}$ and $14 \mathrm{~h}$. We report the results of a gas-phase study of deamination of the protonated nucleosides adenosine $1 \mathrm{r}(\mathbf{1}, \mathrm{R}=$ ribose), guanosine $2 \mathrm{r}(2, \mathrm{R}=$ ribose) and deoxycytidine $3 \mathrm{~d}(3, \mathrm{R}=$ deoxyribose). The study of the nucleosides is equivalent to the study of the nucleobases $1 \mathrm{~h}-3 \mathrm{~h}$ because of the deglycation in the ESI experiments (vide infra) and the study of the nucleosides is advantageous because of their solubility. We also examined the potential formations of $\mathbf{9}$ and/or $\mathbf{1 0}$ from precursors 13e (ether $\mathrm{R}=\mathrm{CH}_{2} \mathrm{OCH}_{2} \mathrm{CH}_{2} \mathrm{OH}$ ), 1-[(2hydroxyethoxy)methyl]-5-cyanoamino-imidazole-4carboxamide, and 14e, 9-[(2-hydroxyethoxy)-methyl]-2(methylthio)-hypoxanthine. The proton affinities of $\mathrm{N}-$, $\mathrm{O}-$, and S-sites were computed for aniline, for the nucleobases $9 \mathrm{H}$-adenine, $1 \mathrm{H}, 9 \mathrm{H}$-guanine, and $1 \mathrm{H}$-cytosine, for the $(Z, Z)$ - and $(E, Z)$-rotamers of cyanoamine $\mathbf{1 3 h}$ and for the $(Z)$ - and $(E)$-rotamers of 2-thiomethyl- $(1 H, 9 H)$-guanine 14h (Scheme 2) to begin the discussion of the gas-phase ion chemistry. The formation of ammonium ions from the most stable protonated species has been studied by potential energy surface exploration and extensive reaction paths analyses have been performed. The MS analyses in
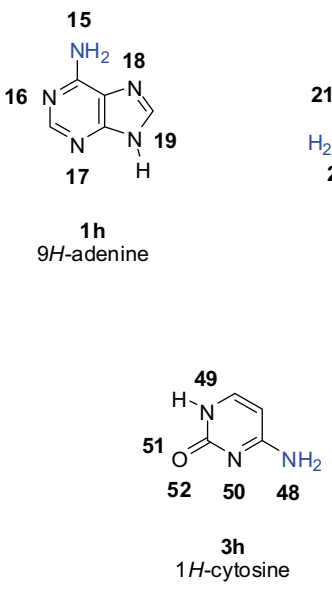
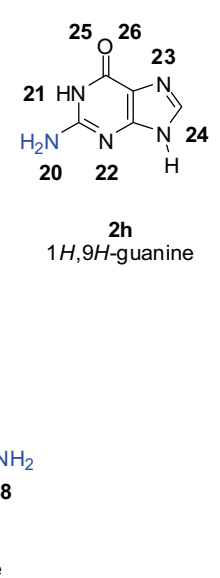

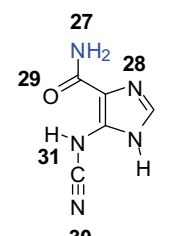

$30(E, Z)-13 h$

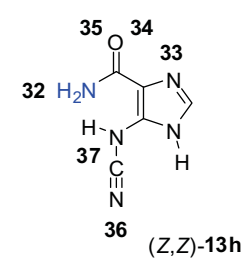

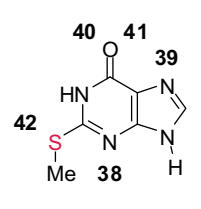

$(Z)-14 h$

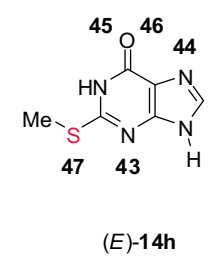

Scheme 2. Conjugate acids formed by protonation of $1 h, 2 h, 3 h, 13 h$, and $14 h$ are numbered according to the protonation sites as indicated. 
Table 1. Voltages for in-source and in-collision cell CID

\begin{tabular}{lccc}
\hline & \multicolumn{2}{c}{ Voltage } & \\
\cline { 2 - 3 } \multicolumn{1}{c}{ Analyte } & $\begin{array}{c}\text { In-source } \\
\text { CID }\end{array}$ & $\begin{array}{c}\text { Collision-cell } \\
\text { CID }\end{array}$ & Figure \\
\hline \hline Adenosine, 1r & & 40 & $1 \mathrm{a}$ \\
Guanosine, 2r & & 30 & $1 \mathrm{~b}$ \\
Deoxycytidine, 3d & & 0 & $1 \mathrm{c}$ \\
{$[\mathbf{1 h}+\mathrm{H}]^{+}, m / z 136$} & 30 & 50 & $2 \mathrm{a}$ \\
{$[\mathbf{8}]^{+}, m / z 119$} & 30 & 35 & $2 \mathrm{~b}$ \\
{$[\mathbf{1 6}]^{+}, m / z 109$} & 60 & 30 & $2 \mathrm{c}$ \\
{$[\mathbf{2 r}+\mathrm{H}-132]^{+}, m / z 152$} & 20 & 50 & $3 \mathrm{a}$ \\
{$[\mathbf{9}]^{+}, m / z 135$} & 40 & 50 & $3 \mathrm{~b}$ \\
{$[\mathbf{2 5}]^{+}, m / z 110$} & 50 & 50 & $3 \mathrm{c}$ \\
{$[\mathbf{1 3 r}+\mathrm{H}]^{+}, m / z 226$} & & 20 & $4 \mathrm{a}$ \\
{$[\mathbf{1 3 h}+\mathrm{H}]^{+}, m / z 152$} & 30 & 5 & $4 \mathrm{~b}$ \\
{$[\mathbf{1 4 r}+\mathrm{H}]^{+}, m / z$ 257 } & & 35 & $4 \mathrm{c}$ \\
{$[\mathbf{1 2 h}+\mathrm{H}]^{+}, m / z 112$} & 30 & 50 & 5 \\
\hline
\end{tabular}

conjunction with the computational assessment of pertinent gas-phase reactions provide compelling evidence for pyrimidine ring-opened species.

\section{Experimental and Computational}

Mass analyses were performed on a Thermo Finnigan TSQ7000 triple-quadrupole mass spectrometer (San Jose, CA) equipped with an AP12 source and Performance
Pack. For all experiments, the heated capillary was maintained at $250{ }^{\circ} \mathrm{C}$ and the electrospray voltage was $4.5 \mathrm{kV}$. Voltages for in-source collision-induced dissociation and collision-induced dissociation [25] (CID) in the collision cell were optimized for each sample (Table 1). Other instrument parameters were optimized as part of biweekly maintenance and tuning. LC experiments employed a system that included a P4000 pump, AS3000 auto-sampler, and UV 6000 photodiode array detector.

For each of the three nucleosides, direct infusion MS experiments showed that the protonated nucleoside is the overwhelmingly dominant ion produced. In-source CID was used to promote deglycation of the nucleosides and to maximize the production of the corresponding protonated nucleobases. Parent ion scans for the protonated nucleobases produced by in-source CID demonstrate that they arise only from the corresponding nucleosides.

The nucleobases were further fragmented using CID in the collision cell of the mass spectrometer to yield the spectra shown. The overall information derived from the MS/MS experiments is equivalent to an MS/MS/MS experiment for each nucleoside. In some cases, in-source CID was used to deglycosylate the nucleoside and also fragment the nucleobase, giving access to ions further along some of the major degradation pathways and allowing positive identification of the fragments along those pathways.

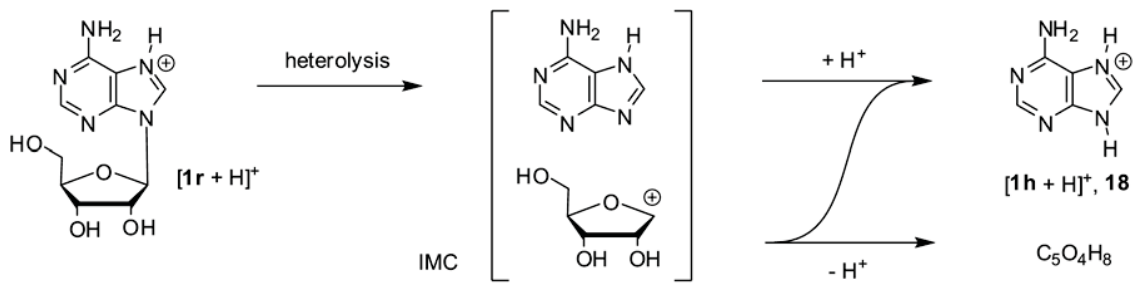

Scheme 3. Conversion of protonated nucleosides to protonated nucleobases.

Table 2. Calculated proton affinities of aniline, the nucleobases cytosine, adenine, and guanine, the $(E, Z)$ - and $(Z, Z)$-rotamers of cyanoamine $13 \mathrm{~h}$, and the $(Z)$ - and $(E)$-rotamers of thioether $14 \mathrm{~h}^{\mathrm{a}}$

\begin{tabular}{|c|c|c|c|c|c|c|c|c|}
\hline Protonation site & Aniline & C & A & G & 13h $(E, Z)$ & $13 \mathrm{~h}(Z, Z)$ & $14 \mathrm{~h}(Z)$ & 14h $(E)$ \\
\hline expt. & $874^{b}$ & $976.4^{\mathrm{c}}$ & $978.0^{\mathrm{c}}$ & $981.4^{\mathrm{c}}$ & & & & \\
\hline $\mathrm{NH}_{2}$ & 879.9 & 819.9 & 848.5 & 793.2 & 831.3 & 894.1 & & \\
\hline $\mathrm{N} 1$ & & $874.6^{\mathrm{d}}$ & 943.8 & $813.6^{d}$ & & & & \\
\hline N3 & & 955.4 & 937.5 & 887.2 & & & 874.1 & 891.6 \\
\hline N7 & & & 909.9 & 959.8 & 876.2 & 923.9 & 944.9 & 946.5 \\
\hline N9 & & & 755.9 & 766.0 & & & & \\
\hline $\mathrm{C} 2-\mathrm{O}, \mathrm{N} 1$ & & 921.6 & & & & & & \\
\hline $\mathrm{C} 2-\mathrm{O}, \mathrm{N} 3$ & & 956.9 & & & & & & \\
\hline $\mathrm{C} 6-\mathrm{O}, \mathrm{N} 1$ & & & & 900.7 & & & 895.9 & 890.2 \\
\hline $\mathrm{C} 6-\mathrm{O}, \mathrm{N} 7$ & & & & 936.3 & & 914.4 & 927.7 & 925.1 \\
\hline $\mathrm{C} 6-\mathrm{O}, \mathrm{NH}_{2}$ & & & & & 868.0 & 872.2 & & \\
\hline NCN, cyano & & & & & 924.5 & 890.2 & & \\
\hline NCN, amino & & & & & 849.4 & 827.7 & & \\
\hline $\mathrm{S}$ & & & & & & & 760.7 & \\
\hline
\end{tabular}

aproton affinities $(\Delta H)$ in $\mathrm{kJ} / \mathrm{mol}$ computed at B3LYP/6-31++ $\mathrm{G}^{* *}$. Data for guanine reported in reference [38]. Compare also [34, 36] for proton affinities of cytosine and adenine, respectively.

${ }^{b}$ Exp. value for aniline from references $[42,43]$.

'Exp. values for nucleobases from reference [40] (p. 9095).

dThese protonated systems are ring-opened structures. 
Table 3. Calculated relative energies and activation barriers ${ }^{\mathrm{a}}$

\begin{tabular}{|c|c|c|c|c|}
\hline Parameter & $\Delta E$ & $\Delta H_{0}$ & $\Delta H_{298}$ & $\Delta G_{298}$ \\
\hline \multicolumn{5}{|l|}{ RE: Adenine 1h } \\
\hline$E_{\text {act, }} 16 \rightarrow 60^{\mp}$ & 203.72 & 191.07 & 189.86 & 191.74 \\
\hline$E_{\text {act }}, \mathbf{1 7} \rightarrow \mathbf{6 1 ^ { \ddagger }}$ & 175.40 & 164.26 & 162.42 & 164.50 \\
\hline$E_{\text {act }}, 16 \rightarrow 62^{\ddagger}$ & 279.83 & 263.29 & 266.26 & 259.51 \\
\hline$E_{\mathrm{rel}}, 63$ vs. 16 & 279.64 & 263.57 & 268.67 & 256.76 \\
\hline$E_{\text {act }}, 63 \rightarrow 64^{\ddagger}$ & 60.67 & 59.54 & 57.24 & 48.90 \\
\hline $\begin{array}{l}E_{\text {rel, }} 63 \text { vs. } 65 \\
\text { RE: Guanine } 2 \mathrm{~h}\end{array}$ & 60.42 & 59.75 & 59.55 & 58.97 \\
\hline$E_{\text {act }} 23 \rightarrow 74^{\ddagger}$ & 303.46 & 293.24 & 294.54 & 290.16 \\
\hline$E_{\text {rel }}, 75$ vs. 23 & 131.27 & 119.88 & 123.81 & 112.97 \\
\hline$E_{\text {act }}, \mathbf{7 5} \rightarrow \mathbf{7 6}^{\ddagger}$ & 32.02 & 30.85 & 29.43 & 32.15 \\
\hline$E_{\text {rel }}, 77$ vs. 75 & 7.96 & 7.62 & 7.41 & 7.96 \\
\hline$E_{\mathrm{act}}, \mathbf{7 7} \rightarrow \mathbf{7 8}^{\ddagger}$ & 84.79 & 73.45 & 72.36 & 74.70 \\
\hline$E_{\mathrm{rel}}, 79$ vs. 77 & 39.14 & 39.10 & 39.81 & 38.51 \\
\hline$E_{\mathrm{act},}, \mathbf{2 3} \rightarrow \mathbf{8 0 ^ { \ddagger }}$ & 268.54 & 251.04 & 251.29 & 249.31 \\
\hline$E_{\mathrm{rel}}, \mathbf{8 1}$ vs. 23 & 22.18 & 20.63 & 21.30 & 20.04 \\
\hline$E_{\text {act }}, \mathbf{8 1} \rightarrow \mathbf{8 2}^{\ddagger}$ & 220.27 & 209.13 & 207.08 & 210.68 \\
\hline$E_{\text {rel }}, \mathbf{8 3}$ vs. 81 & 126.85 & 128.98 & 128.36 & 129.01 \\
\hline$E_{\text {act }}, \mathbf{8 1} \rightarrow \mathbf{8 4 ^ { \ddagger }}$ & 235.28 & 224.23 & 222.30 & 225.54 \\
\hline$E_{\mathrm{rel}}, \mathbf{8 5}$ vs. 81 & 156.34 & 157.43 & 157.39 & 156.49 \\
\hline$E_{\text {act }}, \mathbf{2 3} \rightarrow \mathbf{8 6}^{\ddagger}$ & 215.12 & 204.06 & 202.39 & 205.24 \\
\hline$E_{\text {rel }}, 87$ vs. 23 & 124.47 & 126.56 & 126.73 & 124.12 \\
\hline$E_{\text {rel }}, 22$ vs. 23 & 75.60 & 71.33 & 72.79 & 69.90 \\
\hline$E_{\text {rel, }} 22$ vs. 81 & 53.41 & 50.69 & 51.49 & 49.85 \\
\hline$E_{\text {act }}, 22 \rightarrow 8^{\ddagger}$ & 243.33 & 232.11 & 230.19 & 233.57 \\
\hline$E_{\mathrm{rel}}, 89$ vs. 22 & 167.90 & 167.90 & 168.32 & 166.18 \\
\hline$E_{\text {act }}, \mathbf{2 2} \rightarrow \mathbf{9 1}^{\mathbf{}}$ & 172.77 & 165.90 & 166.07 & 163.47 \\
\hline$E_{\mathrm{rel},}, 92$ vs. 22 & 150.79 & 148.36 & 148.48 & 144.88 \\
\hline$E_{\mathrm{act}}, \mathbf{2 2} \rightarrow \mathbf{9 0 ^ { \ddagger }}$ & 195.97 & 185.88 & 183.28 & 187.95 \\
\hline$E_{\text {rel }}, 20$ vs. 22 & 91.37 & 137.22 & 94.05 & 96.01 \\
\hline$E_{\text {rel, }}, 21$ vs. 23 & 152.19 & 142.68 & 146.45 & 136.28 \\
\hline$E_{\text {act }}, \mathbf{2 1} \rightarrow \mathbf{9 3}^{\ddagger}$ & 239.08 & 225.89 & 224.97 & 224.73 \\
\hline$E_{\mathrm{rel}}, 94$ vs. 21 & 126.37 & 127.21 & 127.59 & 125.98 \\
\hline $\begin{array}{l}E_{\text {act, }} 95 \rightarrow \text { TS }\left(95,10^{\prime}\right) \\
\text { RE: Model } 13 \mathrm{~h}\end{array}$ & 194.02 & 178.41 & 162.71 & 164.25 \\
\hline$E_{\mathrm{rel}}, 13 \mathrm{~h},(Z, Z)$ vs. $(E, Z)$ & 60.55 & 60.42 & 60.42 & 60.07 \\
\hline$E_{\text {act }}, 103 \rightarrow 104^{\ddagger}$ & 50.06 & 44.66 & 39.34 & 38.30 \\
\hline$E_{\mathrm{rel}}, 105$ vs. 103 & 27.12 & 24.86 & 25.87 & 23.27 \\
\hline$E_{\text {act }}, 105 \rightarrow 106^{\ddagger}$ & 183.54 & 170.68 & 170.27 & 170.58 \\
\hline$E_{\text {rel}}, 107$ vs. 105 & 38.57 & 38.91 & 39.49 & 37.68 \\
\hline$E_{\text {act }}, 103 \rightarrow 108^{\ddagger}$ & 77.23 & 76.06 & 74.72 & 76.71 \\
\hline$E_{\mathrm{rel}}, 109$ vs. 103 & -0.92 & -1.00 & -0.88 & -1.46 \\
\hline$E_{\mathrm{act}}, 109 \rightarrow 110^{\ddagger}$ & 54.20 & 43.14 & 42.22 & 43.87 \\
\hline$E_{\mathrm{rel}}, 111$ vs. 109 & 1.84 & 1.38 & 1.92 & 0.51 \\
\hline$E_{\mathrm{act}}, 111 \rightarrow 112^{\ddagger}$ & 44.76 & 43.51 & 42.04 & 44.76 \\
\hline$E_{\text {rel, }}, 113$ vs. 111 & 42.87 & 41.53 & 42.20 & 39.41 \\
\hline$E_{\text {act, }}, 113 \rightarrow 114^{\ddagger}$ & 71.75 & 60.44 & 58.89 & 62.88 \\
\hline$E_{\mathrm{rel}}, 107$ vs. 113 & 21.91 & 21.86 & 22.12 & 22.49 \\
\hline$E_{\text {rel, }} 118$ vs. 107 & 29.82 & 29.90 & 29.40 & 30.67 \\
\hline$E_{\text {rel}}, 118$ vs. 103 & 95.51 & 93.67 & 94.76 & 91.63 \\
\hline$E_{\mathrm{act}}, 28 \rightarrow 121^{\ddagger}$ & 95.40 & 85.52 & 83.59 & 89.47 \\
\hline$E_{\text {rel, }}, 27$ vs. 28 & 40.66 & 42.71 & 42.46 & 44.99 \\
\hline$E_{\mathrm{act}}, 33 \rightarrow 122^{\ddagger}$ & 57.68 & 47.25 & 45.16 & 50.24 \\
\hline$E_{\mathrm{rel}}, 123$ vs. 33 & 41.50 & 42.68 & 41.71 & 45.00 \\
\hline$E_{\mathrm{rel},}, 28$ vs. 103 & 46.28 & 47.16 & 48.41 & 43.21 \\
\hline$E_{\mathrm{rel}}, 33$ vs. 103 & 57.84 & 60.22 & 61.02 & 58.11 \\
\hline $\begin{array}{l}E_{\text {act'}} \mathbf{9} \rightarrow \mathrm{TS}(\mathbf{9}, \mathbf{1 2 5}) \\
\text { RE: Model } \mathbf{1 4 h}\end{array}$ & 294.63 & 289.27 & 286.34 & 294.88 \\
\hline$E_{\text {act }}, 39 \rightarrow 128^{\ddagger}$ & 267.85 & 250.14 & 250.52 & 247.38 \\
\hline$E_{\mathrm{rel},}(Z)-129$ vs. 39 & 33.97 & 32.92 & 31.12 & 35.40 \\
\hline$E_{\mathrm{act}}(Z)-129 \rightarrow 130^{\ddagger}$ & 15.22 & 15.14 & 13.13 & 17.96 \\
\hline$E_{\mathrm{rel}{ }^{\prime}}(E)-129$ vs. $(Z)-129$ & -1.11 & -1.24 & -1.11 & -1.74 \\
\hline$E_{\text {act }}(Z)-129 \rightarrow 131^{\ddagger}$ & 231.37 & 214.45 & 214.03 & 215.04 \\
\hline$E_{\mathrm{rel},}(E)-132$ vs. $(Z)-129$ & 179.15 & 169.27 & 169.98 & 168.13 \\
\hline
\end{tabular}

Table 3. Continued

\begin{tabular}{|c|c|c|c|c|}
\hline Parameter & $\Delta E$ & $\Delta H_{0}$ & $\Delta H_{298}$ & $\Delta G_{298}$ \\
\hline$E_{\text {act }}(E)-129 \rightarrow 133^{\ddagger}$ & 212.53 & 195.41 & 194.78 & 196.67 \\
\hline$E_{\mathrm{rel},}(E)-134$ vs. $(E)-129$ & 171.44 & 161.69 & 162.19 & 159.80 \\
\hline$E_{\mathrm{rel},}(Z)-134$ vs. $(E)-134$ & 15.04 & 14.37 & 14.70 & 12.75 \\
\hline$E_{\mathrm{act} \prime}(Z)-39 \rightarrow 135^{\ddagger}$ & 293.51 & 281.58 & 283.84 & 277.92 \\
\hline $\begin{array}{l}E_{\text {rell}}, 136 \text { vs. }(Z)-39 \\
\text { RE: Cytosine } 3 \mathrm{~h}\end{array}$ & 122.22 & 109.32 & 114.22 & 99.48 \\
\hline$E_{\mathrm{act}}, \mathbf{5 0} \rightarrow \mathbf{1 3 8}^{\ddagger}$ & 241.60 & 227.99 & 227.07 & 228.31 \\
\hline$E_{\mathrm{rel}}, 48$ vs. 50 & 141.80 & 141.38 & 142.09 & 139.41 \\
\hline$E_{\text {act }}, 50 \rightarrow 139^{\ddagger}$ & 364.07 & 349.34 & 352.02 & 343.21 \\
\hline$E_{\text {rel, }}, 140$ vs. 50 & 230.92 & 226.65 & 227.32 & 224.54 \\
\hline$E_{\mathrm{act}}, \mathbf{5 0} \rightarrow \mathbf{1 4 1 ^ { \ddagger }}$ & 320.02 & 305.45 & 308.22 & 300.89 \\
\hline$E_{\mathrm{rel},}, 142$ vs. 50 & 77.96 & 70.38 & 74.27 & 64.24 \\
\hline$E_{\mathrm{act},}, \mathbf{1 4 2} \rightarrow \mathbf{1 4 3 ^ { \ddagger }}$ & 240.50 & 227.31 & 226.35 & 227.31 \\
\hline$E_{\text {rel }}, 144$ vs. 142 & 143.76 & 143.76 & 144.17 & 142.05 \\
\hline$E_{\mathrm{act}}, \mathbf{5 0} \rightarrow \mathbf{1 4 5 ^ { \ddagger }}$ & 341.93 & 327.70 & 315.89 & 310.08 \\
\hline$E_{\text {rel, }}, 146$ vs. 50 & 87.79 & 80.76 & 77.87 & 67.13 \\
\hline
\end{tabular}

aAll data in $\mathrm{kJ} / \mathrm{mol}$ and determined at $\mathrm{B} 3 \mathrm{LYP} / 6-31++\mathrm{G}^{* *}$.

Adenosine, guanosine, and deoxycytidine were purchased from Sigma (St. Louis, MO) and used without further purification. Samples were prepared by dissolving $1 \mathrm{mg}$ nucleoside in $1 \mathrm{~mL}$ of $1 \%$ acetic acid solution. The preparations of the cyanoamine 13 and the thioether 14 have been described previously [21]. The LC-MS studies were performed with a Waters XTerra analytical column (C18, $5 \mu \mathrm{m}, 4.5 \times 250 \mathrm{~mm}$, Milford, MA) using a solvent gradient (Solvents $\mathrm{A}$ and $\mathrm{B}$ are $0.1 \%$ formic acid and acetonitrile, $1 \% \mathrm{~B}$ at $1 \mathrm{~min}, 10 \% \mathrm{~B}$ at $3 \mathrm{~min}, 40 \% \mathrm{~B}$ at 20 $\mathrm{min}, 1 \% \mathrm{~B}$ at $22 \mathrm{~min}$ ) at a flow rate of $1.0 \mathrm{~mL} / \mathrm{min}$ while monitoring at $\lambda=254 \mathrm{~nm}$.

The structures of the nucleobases and the models of their conjugate acids, and of various intermediates and transition states along relevant reaction paths were determined with density functional theory (DFT) [26]. The hybrid method B3LYP was employed in conjunction with the $6-31++G^{* *}$ basis set, B3LYP $/ 6-31++G^{* *}$, and the calculations were performed with Gaussian03 [27] on a 64-processer SGI Altix system (Sunnyvale, CA). Structures were optimized and vibrational analysis was performed for each structure to confirm that the structure was in fact stationary, to confirm the character of the stationary structure, and to determine thermochemical data. Total energies $E$, vibrational zero-point energies $V Z P E$, thermal energies $T E$, and entropies $S$ are tabulated in Supplementary Material section, which can be found in the electronic version of this article, and Cartesian coordinates of all optimized structures are provided there as well. These data allow for the determination of relative and reaction energies $\Delta E$, enthalpies $\Delta H_{0}=\Delta(E+V Z P E)$ and $\Delta H_{298}=\Delta(E+T E)$, and free energies $\Delta G=\Delta(E+T E-298.15 \cdot S)$. Unless otherwise noted, we report $\Delta H_{298}$ values in $\mathrm{kJ} / \mathrm{mol}$, Table 2 provides for an overview of proton affinities, and in Table 3 are listed relevant relative and activation energies. 


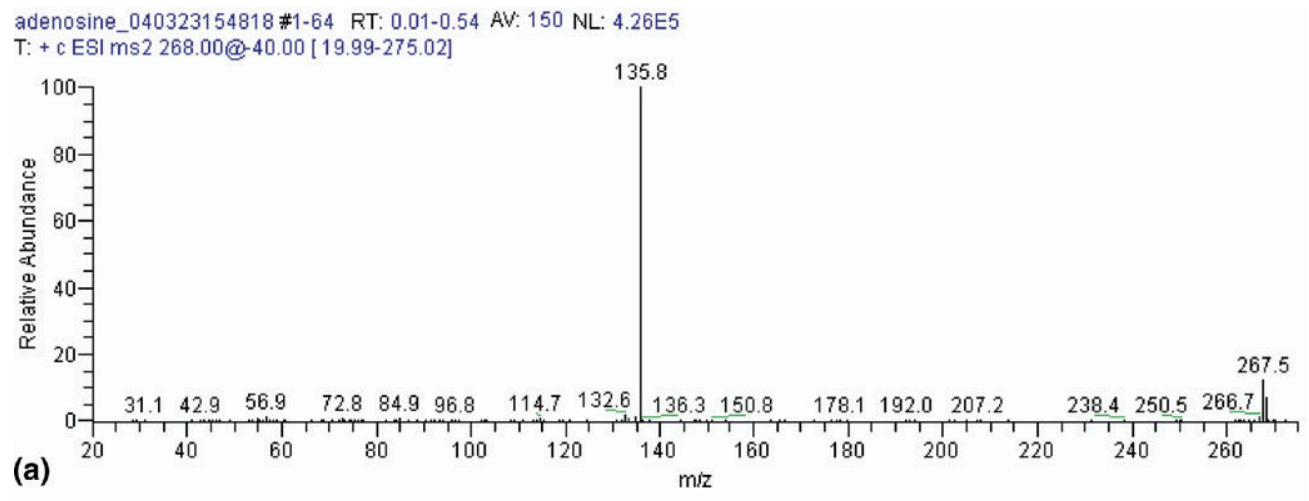

guanosine_040323152231 \#1-150 RT: 0.01-1.27 AV: 150 NL: $1.23 E 6$

T: + c ESI ms2 284.00@-30.00 [19.99-290.01]

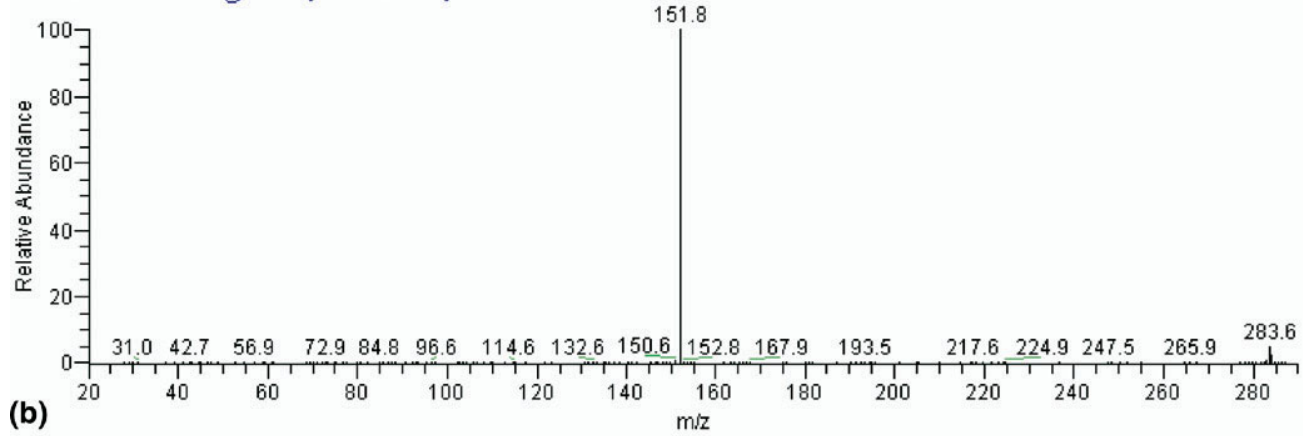

deoxycytidine \#1-150 RT: 0.00-1.27 AV: 150 NL: 1.58E6

$\mathrm{T}:$ + c ESI ms [ 29.98-359.97]

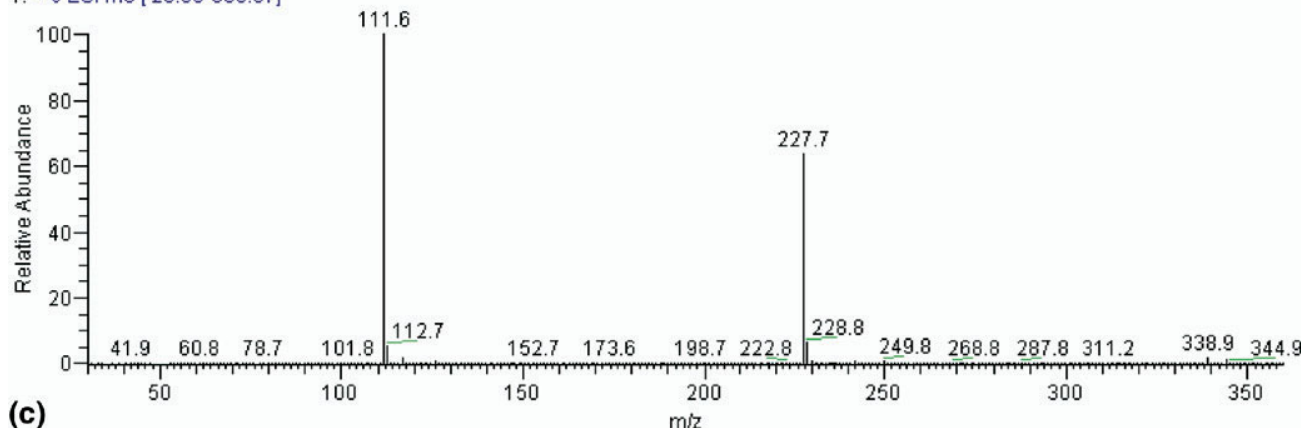

Figure 1. Product-ion spectra of (a) protonated adenosine $[1 \mathbf{r}+\mathrm{H}]^{+}, m / z 268$, and (b) protonated guanosine $[2 \mathbf{r}+\mathrm{H}]^{+}, m / z$ 284. (c) The mass spectrum of deoxycytidine features $[3 \mathbf{d}+\mathrm{H}]^{+}, m / z 228$, and $[3 \mathrm{~h}+\mathrm{H}]^{+}, m / z 112$.

\section{Results and Discussion}

\section{Initial Expulsion of Nitrile or Ammonia}

The mass spectra of the nucleobases have been studied using electron-impact ionization many years ago [28]. The EI study of adenine showed that the major fragmentation path involves successive loss of $\mathrm{HCN}$ molecules. Studies of labeled adenines $[29,30]$ demonstrated that the initially eliminated $\mathrm{HCN}$ contains the $\mathrm{N} 1$ atom and the loss of the $\mathrm{NH}_{2}$ group was not observed. For guanine, the initial expulsion of neutral cyanamide $\left(\mathrm{H}_{2} \mathrm{NCN}\right)$ is the dominant fragmentation (from the pyrimidine's N1-C2- $\mathrm{NH}_{2}$ moiety), and some $\mathrm{NH}_{2}$ group elimination was observed as well. For cytosine [31], $\mathrm{NH}_{2}$ elimination was observed and it is followed by loss of HCN. Initial decarbonylation of the molecular ion also was observed, and the peaks at $\mathrm{m} / \mathrm{z}$
69,68 , and 67 were explained by retro-Diels-Alder reactions eliminating first $\cdot \mathrm{N}=\mathrm{C}=\mathrm{O}, \mathrm{HNCO}$, or $\mathrm{H}$ and $\mathrm{HNCO}$, respectively, and subsequent $\mathrm{HCN}$ loss. Alternatively, the $\mathrm{m} / \mathrm{z} 95$ peak might be due to $\mathbf{1 1 h}(\mathbf{1 1}, \mathrm{R}=\mathrm{H})$ as well as $\mathbf{1 2 h}$, and the peak $\mathrm{m} / \mathrm{z} 68$ could be explained as the result of elimination of $\mathrm{HCN}$ or $\mathrm{HNC}$ from $12 \mathrm{~h}$ and the formation of protonated isocyanatoethyne. Hence, the observation of $\mathrm{m} / \mathrm{z} 68$ might present a first indication for the possible existence of $\mathbf{1 2}$.

\section{ESI and Deglycation}

Electrospray ionization (ESI) mass spectrometry of the nucleosides is employed in the diagnosis of purine and pyrimidine metabolic disorders. Fryèák et al. [32] reported that the dominant fragmentation of the nucleoside molec- 

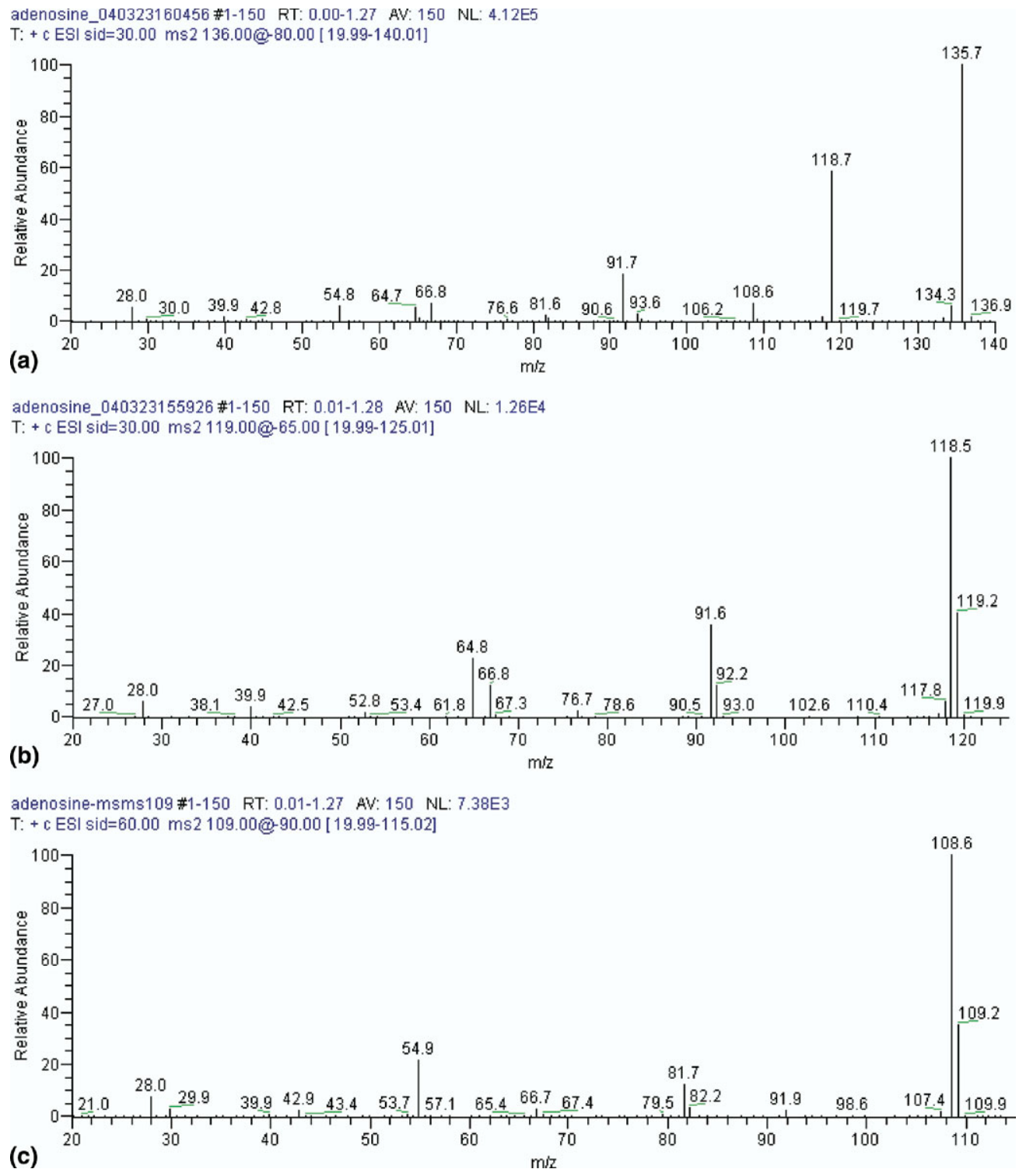

Figure 2. Product-ion spectra of (a) $[\mathbf{1 h}+\mathrm{H}]^{+}, m / z 136,(\mathbf{b}) \mathbf{8}^{\prime}, \mathrm{m} / z$ 119, and (c) $\mathbf{1 6}, \mathrm{m} / \mathrm{z} 109$. All of these precursor ions were produced by in-source fragmentation of $[1 \mathbf{r}+\mathrm{H}]^{+}$at increasing energies.

ular ions is the collision-induced dissociation of the glycosidic C $-\mathrm{N}$ bonds and leads to the replacement of the sugar moiety by a hydrogen atom, as had been suggested by McCloskey [33a]. The process is shown in Scheme 3 for the conversion of adenosine $1 \mathrm{r}(\mathbf{1}, \mathrm{R}=$ ribose $)$ to adenine 1h $(\mathbf{1}, \mathrm{R}=\mathrm{H})$ and assuming N7-protonation [32]. The resulting ion forms an ion-molecule complex (IMC) by heterolysis of the glycosidic $\mathrm{C}-\mathrm{N}$ bond and the intermittent neutral purine is protonated by the oxocarbenium sugar moiety. The spectra in Figure 1 demonstrate these deglycation reactions for $\mathbf{1 r}, \mathbf{2 r}$, and $\mathbf{3 d}$. McCloskey et al. studied the CID spectra of protonated adenine [33b] and protonated guanine [33c]. More recently, Tureček et al. [34] and Wang et al. [35] reported on their experimental and computational studies of protonated cytosine, Tureček et al. [36] explored the dissociation mechanisms of protonated adenine in detail, and we will refer to these reports in the Discussion.

\section{Site of Protonation and Mode of Initial Fragmentation}

The computed proton affinities (Table 2) show that the theoretical level employed presents an acceptable compromise between desired accuracy and computational demand [37]; the computed proton affinities are within $5 \%$ of the experimental values.

There is general agreement with earlier theoretical studies of the purine bases [36-40] and of cytosine [34, 41]. The measured proton affinity of aniline is $874 \mathrm{~kJ} / \mathrm{mol}$ (208.8 [42] and $209.5 \mathrm{kcal} / \mathrm{mol}$ [43] )and experimental [44] and theoretical [45] studies showed almost equal propensity for protonation at the amino-N- and the para-C-atoms. The proton affinities of the amino group of the nucleobases are lower than for aniline and, moreover, amino group protonation cannot compete with the alternatives (Table 2). Guanine prefers imidazole ring protonation 


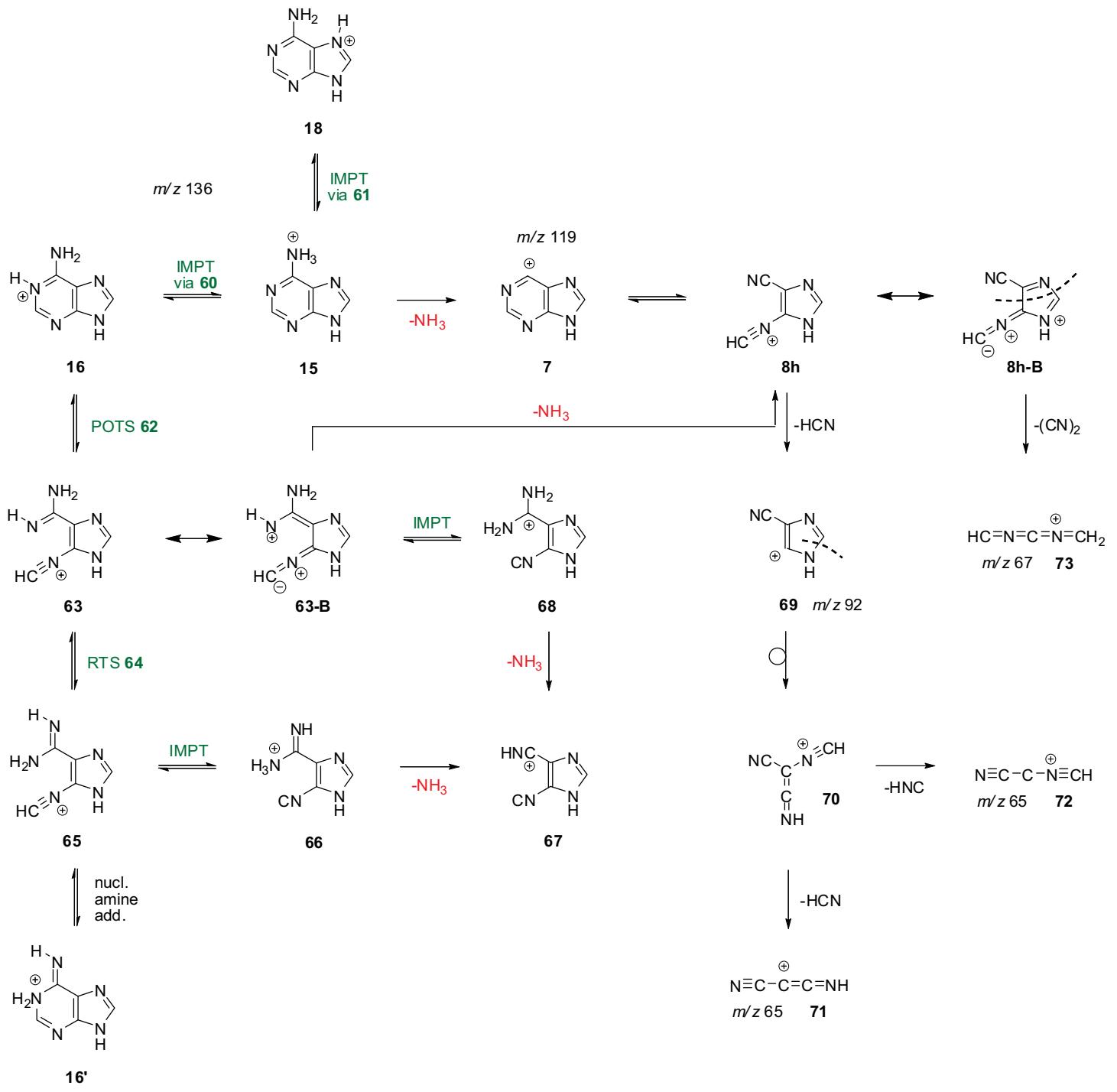

Scheme 4. Fragmentation paths of protonated adenine beginning with $\mathrm{NH}_{3}$ elimination.

with carbonyl-O protonation being a close second, adenine prefers pyrimidine ring protonations, and for cytosine the proton affinities for N3- and O-protonation are similar.

The amino group is not the best protonation site for the nucleobases and the model systems, and we have to discuss how the amino group can serve as the dissociative protonation site [46] or consider alternative mechanisms for ammonia elimination. Some guidance is provided by the emerging understanding of $\mathrm{NH}_{3}$ elimination from peptides [47]. The "mobile proton model" holds that intramolecular proton migration to various protonation sites can occur before fragmentation. In cases with impediments to proton mobility [48], the ammonia elimination might occur as the result of complex mechanisms $[49,50]$. Hence, the potential energy surfaces of the protonated systems were explored to search for and to determine the energy profiles of paths for proton migration leading to the formation of ammonium ions.

\section{ESI-MS/MS of Adenosine}

The mass spectrum of electrosprayed adenosine gave two peaks as shown in Figure 1. $m / z 268[1 \mathbf{r}+\mathrm{H}]^{+}$is protonated adenosine and $m / z 136[\mathbf{1 h}+\mathbf{H}]^{+}$results by cleavage of the glycosidic $\mathrm{C}-\mathrm{N}$ bond. Mass selection for $m / z 136$ and application of CID results in the spectrum of Figure 2, the mechanisms of the fragmentation of the quasimolecular ion $\mathrm{m} / \mathrm{z} 136$ are outlined in Scheme 4, and molecular models of relevant intermediates and transition-state structures are shown in Scheme 5 .

The minor paths for fragmentation of ion $[1 \mathbf{h}+\mathrm{H}]^{+}$ involve initial loss of $\mathrm{HCN}$ or $\mathrm{NH}_{2} \mathrm{CN}$ and these are the fragmentations observed in EI-MS. The MS/MS analysis of ion 53 (Figure 2c) shows the formations of ions $54(\mathrm{~m} / \mathrm{z}$ $82)$ and $55(\mathrm{~m} / \mathrm{z} 55)$ by successive losses of three HCN and resulting in the formation of $\mathbf{5 6}(\mathrm{m} / \mathrm{z} 28)$, protonated $\mathrm{HCN}$. Initial elimination of cyanoamine leads to $57(\mathrm{~m} / \mathrm{z} 94)$ and 


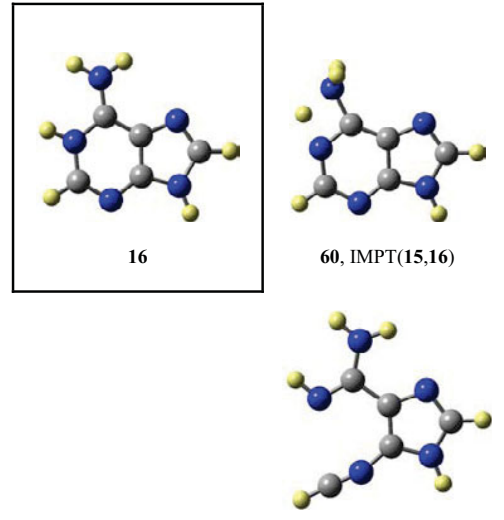

62, $\operatorname{POTS}(16,63)$
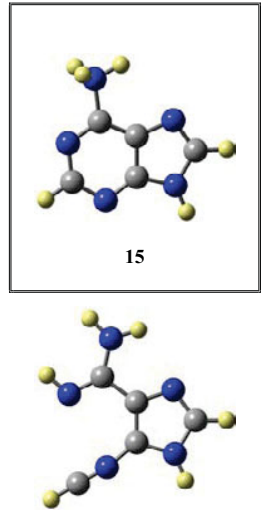

63

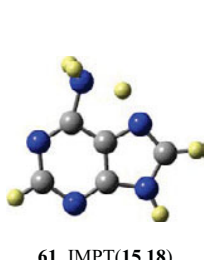

61, $\operatorname{IMPT}(15,18)$

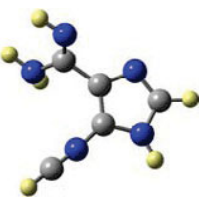

64, $\operatorname{RTS}(63,65)$
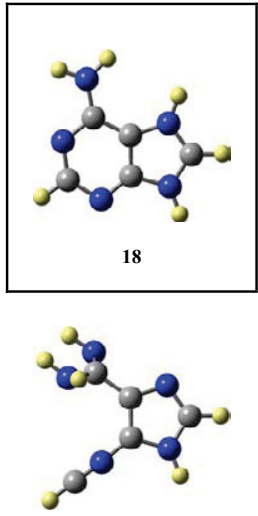

65

Scheme 5. Intramolecular proton transfer allows for the conversions of N1- and N7-protonated tautomer 16 and 18 (bold single-lined boxes) to the ammonium tautomer 15 (double-lined). Pyrimidine ring-opening of N1-protonated adenine may lead to amidines 63 and 65 but these paths are not competitive.

another HCN (or HNC) elimination cascade from 57 to 58 $(\mathrm{m} / \mathrm{z} 67)$ to $59(\mathrm{~m} / \mathrm{z} 40)$.

Amino protonation is less likely than protonation at N1, N3, or N7 of adenine $\mathbf{1 h}$ (Table 2) and ammonium ion 15 would have to be generated by proton migration within $[1 \mathrm{~h}+\mathrm{H}]^{+}$. Proton transfers from 16 and 18 to 15 via transition-state Structure 60 and Structure 61, respectively, require activation enthalpies of 189.9 and $162.4 \mathrm{~kJ} / \mathrm{mol}$, respectively.

One can also envision the formation of $8 \mathrm{~h}$ by direct $\mathrm{NH}_{3}$ elimination from 63 (consider resonance form 63-B) via 68 or from 65 via 67 if 65 does not reclose to 16' [51]. These options depend on the accessibilities of 63 and 65 . Indeed, 63 and $\mathbf{6 5}$ are minima on the potential energy surface, 63 is preferred over 65 by $\Delta E=60.4 \mathrm{~kJ} / \mathrm{mol}$, and the rotational barrier for the conversion of 63 to 65 via transition-state structure 64 is $\Delta E=60.7 \mathrm{~kJ} / \mathrm{mol}$. With thermal energies considered, this activation barrier vanishes, and 65 becomes the transition-state structure for the rotational automerization of 63 with an activation enthalpy of $\Delta H_{298}=59.6 \mathrm{~kJ} / \mathrm{mol}$. There is hardly any barrier to the back-reaction of 63 via transition-state structure $\mathbf{6 2}$ to 16 , this feature is the hallmark of pseudopericyclic reactions [52], and the relative energy of 63 with regard to 16 is $268.7 \mathrm{~kJ} / \mathrm{mol}$. Tureček et al. [36] showed that 63 plays a crucial role to exchange the N1- and the amino-N atoms in $[\mathbf{1 h}+\mathrm{H}]^{+}$.

The major fragmentation cascade of $[\mathbf{1 h}+\mathrm{H}]^{+}$begins with $\mathrm{NH}_{3}$ elimination from 15 or 63 to yield $8 \mathrm{~h}$ with $\mathrm{m} / \mathrm{z}$ 119 (Figure 2a). The subsequent HCN (or HNC) elimination can be explained conveniently from $8 \mathrm{~h}$. Ion 69 then can rearrange to 70 on its way to ions $m / z 65$, protonated dicyanocarbene 71 and/or its mono-isonitrile isomer 72 (Figure 2b).

We found that ion $\mathrm{m} / \mathrm{z} 119$ also leads to fragments $\mathrm{m} / \mathrm{z}$ 67 and $m / z 40$ (Figure $2 b$ ). The $\mathrm{H}_{3} \mathrm{C}_{3} \mathrm{~N}_{2}{ }^{+}$ion occurs as 58 in the decomposition path initiated by $\mathrm{NH}_{2} \mathrm{CN}$ elimination and an ion with this formula also can form along the major path. Considering resonance form $\mathbf{8 h}-\mathbf{B}$ we propose that $\mathrm{m} / \mathrm{z} 67$ might result by dicyanogen (ethanedinitrile) elimination to form the protonated cumulene 73 .

\section{ESI-MS of Guanosine}

The mass spectrum of electrosprayed guanosine gave a product peak at $m / z 152$ after cleavage of the glycosidic $\mathrm{CN}$ bond (Figure 1). Figure 3 shows the product-ion spectra obtained by CID of $[2 \mathbf{h}+\mathrm{H}]^{+}, m / z 152$, and its two most abundant fragments $\mathrm{m} / \mathrm{z} 135$ and $\mathrm{m} / \mathrm{z} 110$ resulting from $\mathrm{NH}_{3}$ and cyanamide elimination. We considered seven paths, which are shown in Scheme 6; relevant stationary structures are shown in Scheme 7.

The N7-protonated tautomer $\mathbf{2 3}$ is the most stable and most abundant ion of $[2 \mathbf{h}+\mathrm{H}]^{+}$. We first considered the pyrimidine ring-opening of $\mathbf{2 3}$ to $\mathbf{7 4}$ by a pseudopericyclic reaction mechanism. We found that an amidine with a 74-like structure does not correspond to a minimum and, instead, rotation about the $\mathrm{C} 2-\mathrm{N} 3$ bond via transitionstate structure 74 results in amino-group transfer along the down path from 74 to 75 . The computed activation barrier for the reaction $\mathbf{2 3} \rightarrow \mathbf{7 4 ^ { \ddagger }} \rightarrow \mathbf{7 5}$ is $\Delta H_{298}=294.5$ $\mathrm{kJ} / \mathrm{mol}$ and, should 75 be accessible, one could envision the facile formation of $\mathbf{9}^{\prime}$ via 77 and 79. Next, we considered two paths that begin with initial proton migration to 81; the computed activation barrier for the reaction $23 \rightarrow$ $\mathbf{8 0}^{\ddagger} \rightarrow \mathbf{8 1}$ is $\Delta H_{\text {act }}=251.3 \mathrm{~kJ} / \mathrm{mol}$; some $40 \mathrm{~kJ} / \mathrm{mol}$ lower than the path via 74 . The back-reaction of $\mathbf{8 1}$ is less likely than the intramolecular proton transfers $81 \rightarrow 82^{\ddagger} \rightarrow 83$ $\left(\Delta H_{\text {act }}=207.1 \mathrm{~kJ} / \mathrm{mol}\right)$ and $81 \rightarrow 84^{\ddagger} \rightarrow 85\left(\Delta H_{\text {act }}=222.3\right.$ $\mathrm{kJ} / \mathrm{mol}$ ). Ammonium ions 83 and 85 are substrates for the formations of $\mathbf{9}^{\prime}$ and $\mathbf{1 0}$.

The initial proton transfer $\mathbf{2 3} \rightarrow \mathbf{8 1}$ was considered because we thought that $\mathrm{NH}_{3}$ elimination required electrophilic catalysis, that is, the availability of an acidic $\mathrm{H}$ atom for 1,2-elimination. Eventually, we came to wonder whether the N1-hydrogen in 23 might not be acidic enough for the reaction $23 \rightarrow 86^{\ddagger} \rightarrow 87$. In fact, the nonstandard resonance form 23-C makes perfect sense: 

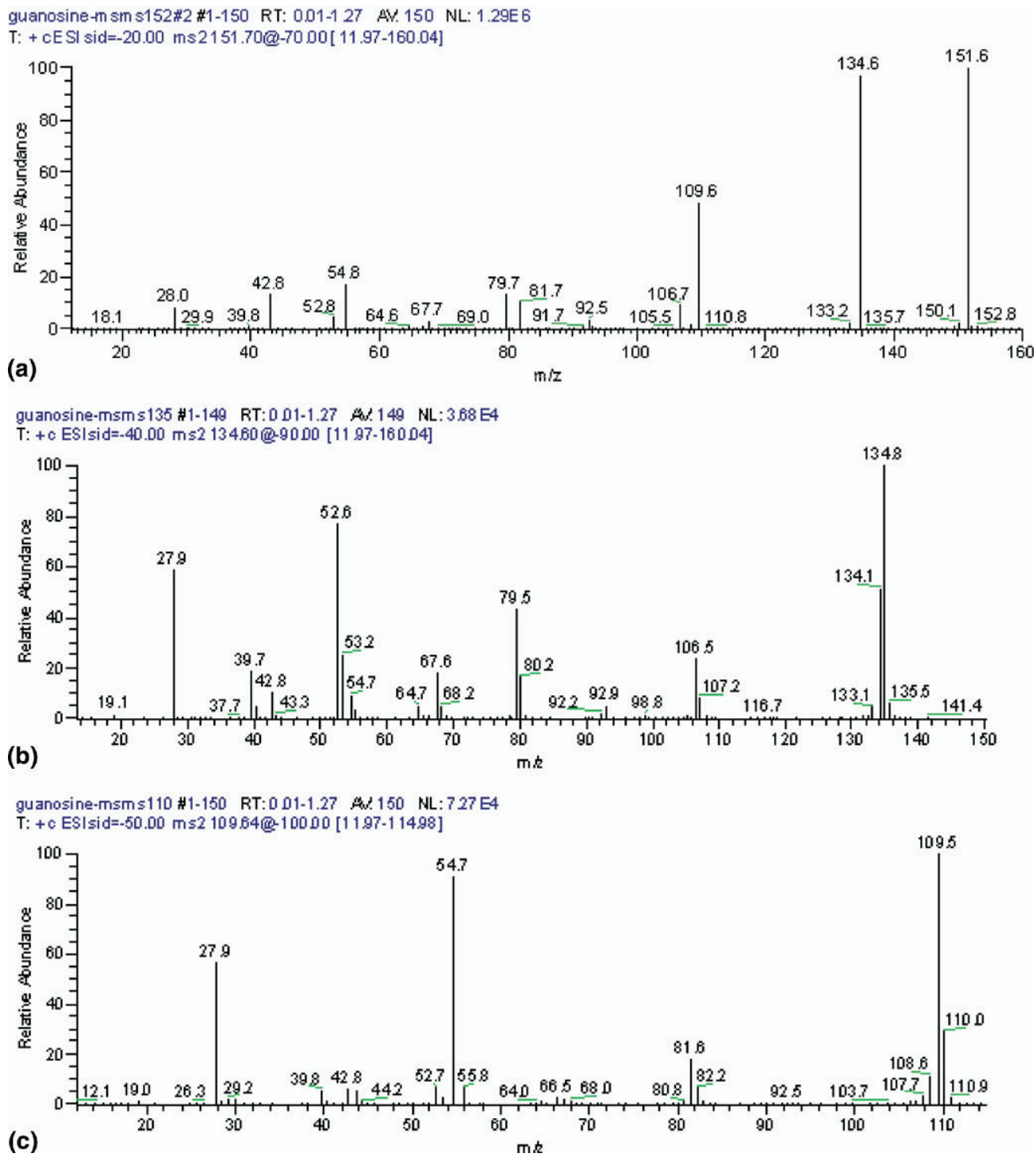

Figure 3. Product-ion spectra of (a) $[\mathbf{2 h}+\mathrm{H}]^{+}, m / z$ 152, (b) $\mathbf{9}^{\prime}, m / z$ 135, and (c) $\mathbf{9 8}, m / z$ 110. All precursors were produced by in-source fragmentation of $[2 \mathbf{r}+\mathrm{H}]^{+}$at increasing energies.

the zwitterion-like $\pi$-polarization is effective to stabilize the charge in the $\sigma$-system caused by N7-protonation. Indeed, reaction $23 \rightarrow 86^{\ddagger} \rightarrow 87$ requires an activation barrier of only $\Delta H_{\text {act }}=202.4 \mathrm{~kJ} / \mathrm{mol}$.

Ion 23 is the most stable tautomer of $\left[2 \mathbf{h}+\mathrm{H}^{+}\right.$and it can be formed directly from $[2 \mathbf{r}+\mathrm{H}]^{+}$. The initial formations of tautomers $\mathbf{2 1}$ and $\mathbf{2 2}$ are possible and their isomerizations to 23 should be fast in the hot ion [ $2 \mathrm{~h}+$ $\mathrm{H}]^{+}$. Nevertheless, the isomerizations $23 \rightarrow 20,23 \rightarrow 21$, and $23 \rightarrow 22$ could be relevant for the fragmentation. The conversion of $\mathbf{2 3}$ to 20 likely would proceed via $\mathbf{8 1}$ and 22 in that sequence. Nevertheless, suppose that 22 were accessible from 23 without going through 81, such a path $\mathbf{2 3} \rightarrow \mathbf{2 2}$ would become interesting only if $\mathbf{2 2}$ were to offer a reaction channel for $\mathrm{NH}_{3}$ elimination with a barrier that was at least $72.8 \mathrm{~kJ} / \mathrm{mol}$ lower than for the reaction $\mathbf{2 3} \rightarrow$ 87. The conversion of $\mathbf{2 3}$ to $\mathbf{2 1}$ is likely to proceed via $\mathbf{2 6}$ and 25 . Since 21 is $146.5 \mathrm{~kJ} / \mathrm{mol}$ less stable than 23 , the path $\mathbf{2 3} \rightarrow \mathbf{2 1}$ becomes interesting if $\mathbf{2 1}$ were to offer any reaction channel for $\mathrm{NH}_{3}$ elimination with a barrier that were at least that much lower than for the reaction $\mathbf{2 3} \rightarrow$ 87. Neither of these options seemed likely, but they were explored to be sure and we computed the reactions $22 \rightarrow$ $88^{\ddagger} \rightarrow 89\left(\Delta H_{\mathrm{act}}=230.2 \mathrm{~kJ} / \mathrm{mol}\right), 22 \rightarrow 90^{\ddagger} \rightarrow 20\left(\Delta H_{\mathrm{act}}=\right.$ $183.3 \mathrm{~kJ} / \mathrm{mol}), 22 \rightarrow \mathbf{9 1}^{\ddagger} \rightarrow \mathbf{9 2}\left(\Delta H_{\mathrm{act}}=166.1 \mathrm{~kJ} / \mathrm{mol}\right)$, and $21 \rightarrow 93^{\ddagger} \rightarrow 94\left(\Delta H_{\text {act }}=225.7 \mathrm{~kJ} / \mathrm{mol}\right)$. The situations with $\mathbf{2 2} \rightarrow \mathbf{9 1} \mathbf{1}^{\ddagger} \rightarrow \mathbf{9 2}$ and $\mathbf{2 3} \rightarrow \mathbf{7 4} 4^{\ddagger} \rightarrow \mathbf{7 5}$ allow for an interesting comparison and an acyclic amidine does not exist in either case. Hence, there are two paths from 22 and one path from 21 to ammonium ions, and the computed activation barriers show that these paths do not offer alternative, low-energy channels.

These results suggest that the reaction $23 \rightarrow 86^{\ddagger} \rightarrow 87$ with its activation barrier of $\Delta H_{\text {act }}=202.4 \mathrm{~kJ} / \mathrm{mol}$ provides the most easily accessible channel to an ammonium ion of $[2 \mathbf{h}+\mathrm{H}]^{+}$, and that $\mathrm{NH}_{3}$ elimination yields 95 , a 


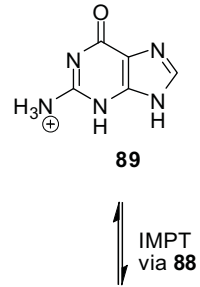

22

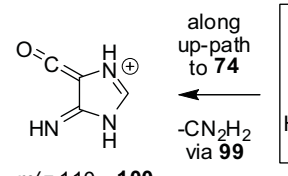

$m / z 110100$
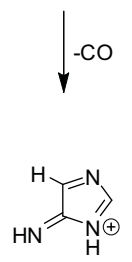

$m / z 82 \quad 101$

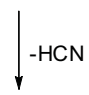

$m / z \quad 55 \quad 102$

$\downarrow-\mathrm{HCN}$

$m / z \quad 28 \quad 56$<smiles>[NH3+]c1nc2[nH]cnc2c(=O)[nH]1</smiles>

20

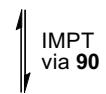<smiles>Nc1nc2[nH]cnc2c(=O)[nH]1</smiles>

22

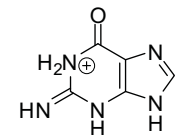

92

IMPT

22
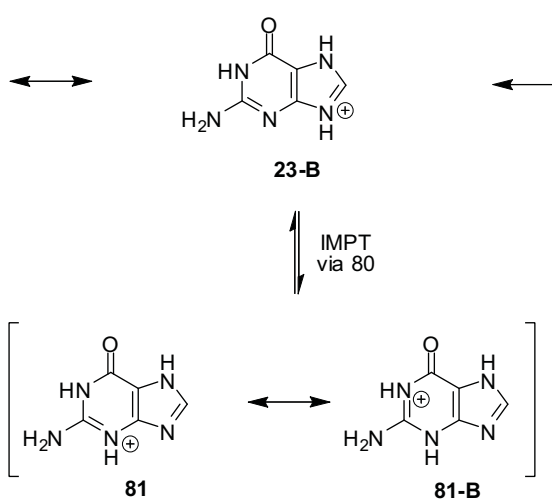

| 1 IMPT 82
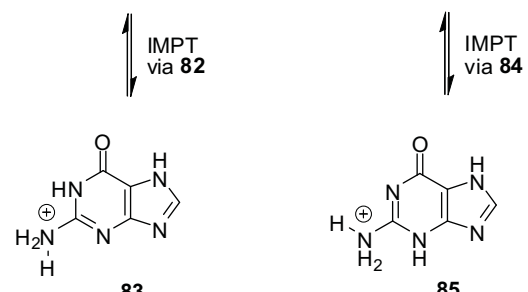

83

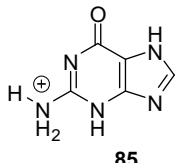

85

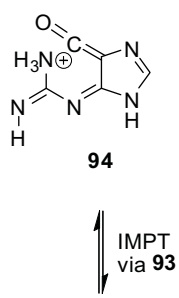

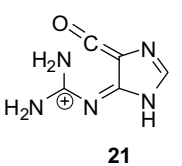

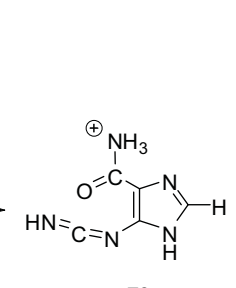

79

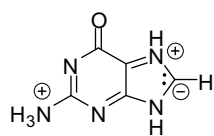

87
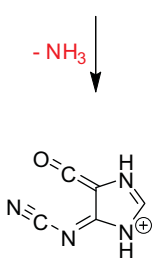

95
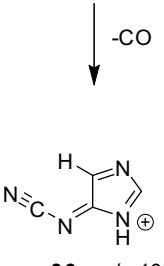

$96 \mathrm{~m} / \mathrm{z} 107$

Scheme 6. Fragmentation paths of protonated guanine $[2 \mathbf{h}+\mathrm{H}]^{+}$.

tautomer of carbodiimides $\mathbf{9}$ and $\mathbf{9}^{\prime}$ and of cyanoimines $\mathbf{1 0}$ and $\mathbf{1 0}^{\prime}$. In the gas phase, the activation barrier for the isomerization between the prototypical carbodiimide and cyanamide is over $330 \mathrm{~kJ} / \mathrm{mol}$ [53]. The tautomerization of $\mathbf{9 5}$ to $\mathbf{1 0}^{\prime}$ requires an activation enthalpy of $\Delta H_{\mathrm{act}}=162.71$ $\mathrm{kJ} / \mathrm{mol}$ but even this low barrier apparently does not allow for competition with decarbonylation and 1,2-Hshift to $96(\mathrm{~m} / \mathrm{z}$ 107). The loss of CO requires the proximity of an $\mathrm{NH}$ site so that the incipient carbene can be stabilized [54]. HCN loss from ion $\mathrm{m} / z 107$ results in $97(\mathrm{~m} / \mathrm{z}$ 80), and 97 can loose another HCN (or HNC) to form $98 \mathrm{~m} / \mathrm{z}$ $\left.53, \mathrm{C}_{2} \mathrm{~N}_{2} \mathrm{H}^{+}\right)$or eliminate dicyanogen to form $56(\mathrm{~m} / \mathrm{z} 28$, $\mathrm{H}_{2} \mathrm{CN}^{+}$).
Initial cyanamide expulsion is the dominant mode of guanosine decomposition in EI-MS, the process leads to the $m / z 110$ ion, and its product-ion spectrum is shown in Figure 3c. It appears likely that $\mathbf{2 3}$ itself is the most suitable precursor for the $\mathrm{NH}_{2} \mathrm{CN}$ elimination. The stage is set for $\mathrm{CN}_{2} \mathrm{H}_{2}$ elimination as soon as the N1-C6 bond of 23 is mostly broken along the up-path to transition-state structure 74. There are many options to accomplish the tasks of second $\mathrm{CN}$ cleavage and proton transfer (from $\mathrm{NH}$ or $\mathrm{NH}_{2}$ to $\mathrm{O}$ or $\mathrm{N}$ ), these elemental reactions could occur within ranges of the up-path to the rotational transitionstate region, and these tasks might occur stepwise or in concert. The PES exploration of reaction $23 \rightarrow 74^{\ddagger} \rightarrow 75$ 

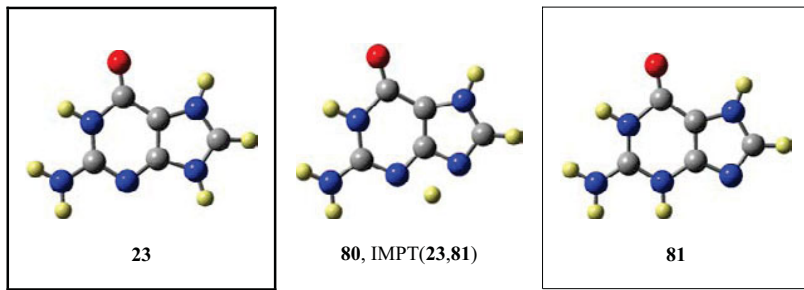

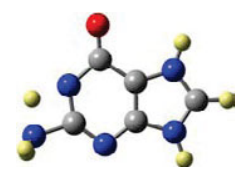

86, $\operatorname{IMPT}(23,87)$

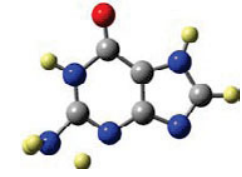

82, IMPT $(\mathbf{8 1}, \mathbf{8 3})$

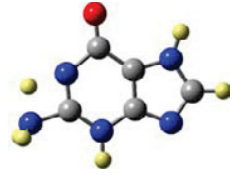

84, IMPT $(81,85)$

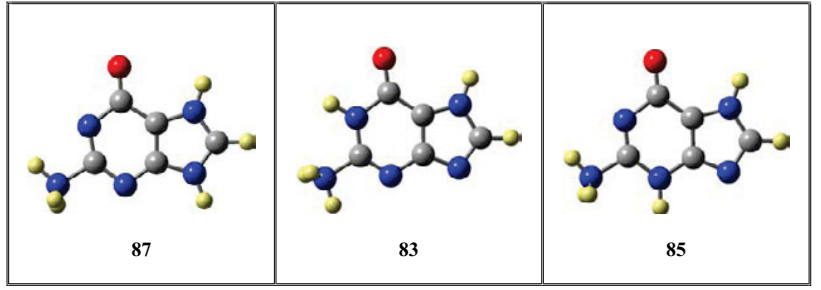

Scheme 7. N7-Protonated guanine 23 (bold single-lined) is the most stable structure of $[2 \mathbf{h}+\mathrm{H}]^{+}$. The paths are shown for the formations of ammonium ion precursor 81 (single-lined) and of their ammonium ions 83, 85, and 87 (double-lined).

suggests, for example, that one amino- $\mathrm{H}$ in a 74-like structure would be well-positioned to transfer to N3, that is, for carbodiimide elimination via transition-state structure 99 and leading directly to 100 (Scheme 6). The prominent peaks with $\mathrm{m} / \mathrm{z}$ values of 82,55 , and 28 further suggest decarbonylation to 101, and $\mathrm{HCN}$ (or HNC) eliminations to $\mathbf{1 0 2}$ and $\mathbf{5 6}$. The possibility of proton transfer to $\mathrm{O}$ along the up-path to 74 cannot be dismissed in and of itself; such a course of reaction would make the CO elimination a complicated affair but not an impossible one.

\section{ESI-MS Spectrometry of 5-Cyanoamino-Imidazole-4-Carboxamide 13e}

We synthesized cyanoamine $13 \mathrm{e}(\mathbf{1 3}$, ether $\mathrm{R}=$ $\mathrm{CH}_{2} \mathrm{OCH}_{2} \mathrm{CH}_{2} \mathrm{OH}$ ) and studied its cyclization reaction and cross-link formation chemistry [21, 22]. The production spectra of $[\mathbf{1 3 e}+\mathrm{H}]^{+}, m / z \mathbf{2 2 6}$, and $[\mathbf{1 3 h}+\mathrm{H}]^{+}, m / z$ 152, are reported in Figure 4. As with Figure 1, the spectrum in Figure $4 \mathrm{a}$ shows the replacement of the R-group by an $\mathrm{H}$-atom to form $[\mathbf{1 3 h}+\mathrm{H}]^{+}, m / z 152$.

Ion $[\mathbf{1 3 h}+\mathrm{H}]^{+}$eliminates ammonia as in the case of $[2 \mathrm{~h}+\mathrm{H}]^{+}$. However, $\left[\mathbf{1 3 h}+\mathrm{H}-\mathrm{NH}_{3}\right]^{+}$does not decarbonylate subsequently and instead loses $\mathrm{CN}$ to form $m / z$ 109. The potential energy surfaces of $\mathbf{1 3}$ and $[\mathbf{1 3}+\mathrm{H}]^{+}$ are complex because of the possibility for rotamers (about both exocyclic bonds) and tautomerism (cyanoamine versus carbodiimide) and a complete discussion will be presented elsewhere while some relevant data are included here. For the present purpose it is important to know that $(E, Z)-\mathbf{1 3 h}$ is preferred over any of the carbodi- imides and also preferred by $\Delta H_{\text {rel }}=60.3 \mathrm{~kJ} / \mathrm{mol}$ over $(Z, Z)-13 h$. Studies of amides suggest that $\mathrm{NH}_{3}$ elimination occurs only from the ammonium ion [55]. Yet, neither carbonyl-O nor amino-N protonation can compete with nitrilium or imidazolium ion formation (Table 2). Hence, we considered paths to ammonium ion formation from nitrilium and imidazolium ions (Scheme 8).

Cyano- $N$ protonation is by far the best option for cyanoamine $(E, Z)-\mathbf{1 3 h}$ and ion $\mathbf{9}$ becomes accessible by $\mathrm{NH}_{3}$ elimination from ammonium ion 107. Cyano- $\mathrm{N}$ protonation of $(E, Z)-\mathbf{1 3 h}$ does not form a stable nitrilium ion $\mathbf{3 0}$ and $\mathrm{O}$-protonated carbodiimide $\mathbf{1 0 3}$ is formed instead. Its rotamer 105 is easily accessible via rotational transitionstate structure $104\left(\Delta H_{\text {act }}=39.3 \mathrm{~kJ} / \mathrm{mol}\right)$ but proton migration (from the OH-donor) $105 \rightarrow 106^{\ddagger} \rightarrow 107$ requires an activation energy of $\Delta H_{\text {act }}=170.3 \mathrm{~kJ} / \mathrm{mol}$. Another path from 103 to 107 via 109 and 111 involves a series of rotations and offers the advantage of forming the ammonium ion by H-shift from the $\mathrm{NH}$-donor $\mathbf{1 1 3}$ with a barrier of only $\Delta H_{\text {act }}=58.9 \mathrm{~kJ} / \mathrm{mol}$. The highest rotational barrier along this path is $\Delta H_{\text {act }}=74.7 \mathrm{~kJ} / \mathrm{mol}$ for the isomerization $\mathbf{1 0 3} \rightarrow \mathbf{1 0 8}^{\ddagger} \rightarrow \mathbf{1 0 9}$ (and this isomerization could be accomplished in three steps with lower activation barriers via intermediates 105 and 116). There are many paths from 103 to 107 and clearly at least some of them are kinetically facile.

As with the formation of $\mathbf{1 0 3}$ from $(E, Z)-\mathbf{1 3 h}$, ion $\mathbf{1 1 8}$ would be easily available by cyano- $\mathrm{N}$ protonation of (Z,Z)-13h. In the absence of $(Z, Z)-\mathbf{1 3 h}$, however, 118 would have to be produced from 116 by H-shift via 120 or by isomerization of $\mathbf{1 0 7}$ via rotational transition-state structure 119. At least the latter path is accessible but none of this matters anyhow because $\mathbf{1 1 8}$ is less stable than 107 by $\Delta H_{\text {rel }}=29.4 \mathrm{~kJ} / \mathrm{mol}$.

The direct formation of $\mathbf{2 8}$ by N7-protonation of $(E, Z)$ 13h would offer the advantage to make ammonium ion 27 accessible via transition-state structure 121 with activation energy $\Delta H_{\text {act }}=83.6 \mathrm{~kJ} / \mathrm{mol}$. Direct protonation of $(\mathrm{Z}, \mathrm{Z})$ 13h favors the formation of imidazolium ion 33 (Table 2) and ammonium ion $\mathbf{1 2 3}$ is then accessible by the H-shift 33 $\rightarrow 122^{\ddagger} \rightarrow 123$ with an activation energy of only $\Delta H_{\text {act }}=$ $41.7 \mathrm{~kJ} / \mathrm{mol}$. Yet, in the MS experiment, 28 and 33 have to be formed from 103 and these ions are 48.4 and 61.0 $\mathrm{kJ} / \mathrm{mol}$ less stable, respectively, than 103 . These relative energies together with the computed barriers to form 27 and $\mathbf{1 2 3}$ show that there are no low-energy alternatives to the formation of ammonium ion $\mathbf{1 0 7 .}$

The potential energy surface of protonated 5-cyanoimino-4-oxomethylene-dihydroimidazole is complicated [24] and we have already seen that it includes rotamers of 9 and $\mathbf{9}^{\prime}$, rotamers of $\mathbf{1 0}$ and 10', and rotamers of 95. In addition, geometrical isomers of O-protonated species also are possible, and it becomes relevant that O-protonation leads to bicyclic ions $\mathbf{1 2 5}$ and $\mathbf{1 2 5}^{\prime}$. Cation 9 prefers the $E$-conformation about the $\mathrm{C}-\left(\mathrm{N}_{2} \mathrm{CH}\right)$ bond and the equilibration $(Z)-9 \rightleftarrows(E)-9$ is facile [19]. The intramolecular H-shift from nitrogen in (E)-9 to the oxygen in $\mathbf{1 2 5}$ requires an activation energy of $\Delta H_{\mathrm{act}}=268.3 \mathrm{~kJ} / \mathrm{mol}$ and the accessibility of $\mathbf{1 2 5}$ 

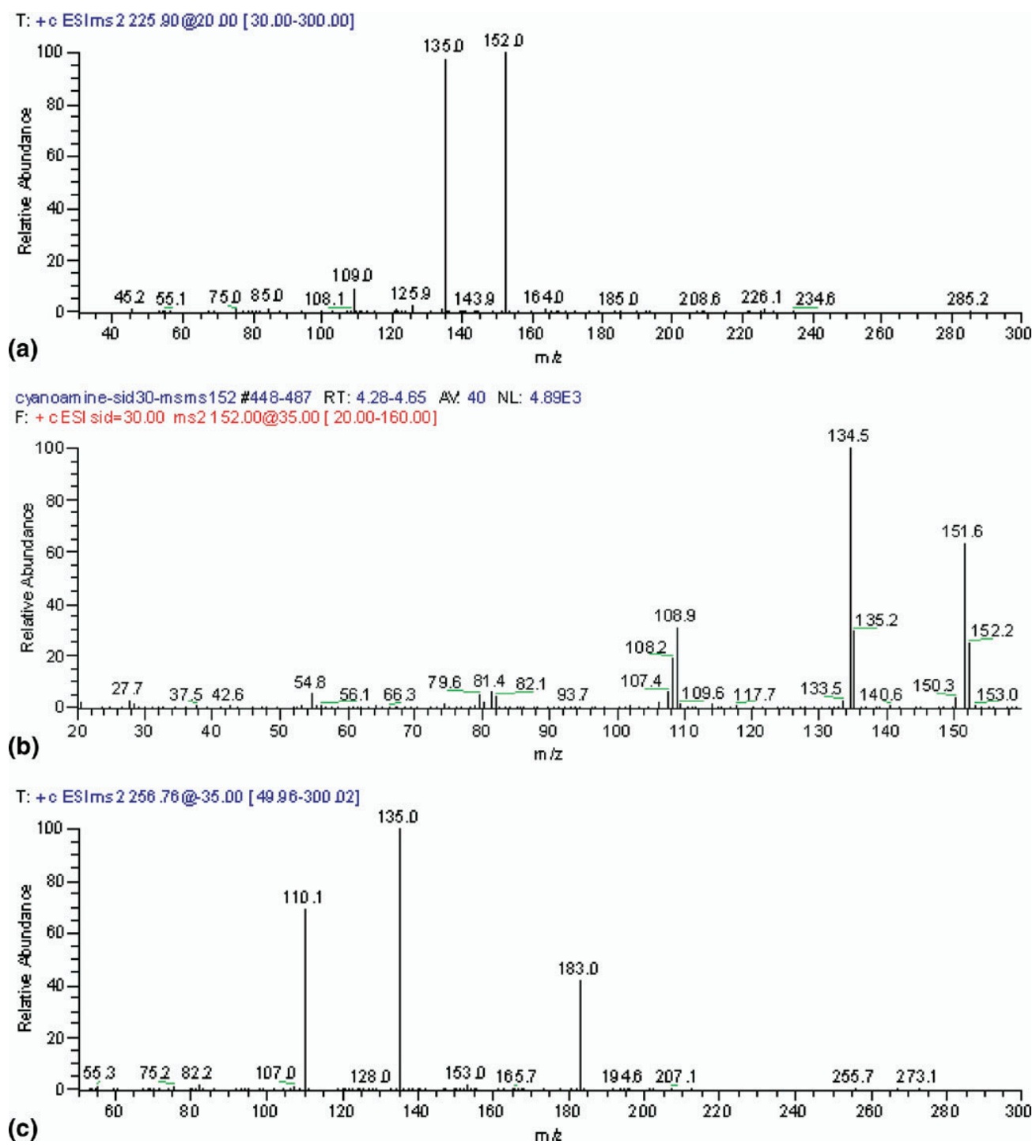

Figure 4. (a) Product-ion spectrum of $[13 r+H]^{+}, m / z$ 226. (b) Product-ion spectrum of $[13 h+H]^{+}$, $m / z 152$, produced by in-source fragmentation of $[13 \mathbf{r}+\mathrm{H}]^{+}$. (c) Product-ion spectrum of $[14 \mathbf{r}+\mathrm{H}]^{+}$, $\mathrm{m} / \mathrm{z} 257$.

provides a rational for $\mathrm{CN}$ elimination from 9 and leading to 126.

\section{ESI-MS Spectrometry of 2-Methylthiohypoxanthine $14 \mathrm{~h}$}

Thioether 14e (14, with ether $\left.\mathrm{R}=\mathrm{CH}_{2} \mathrm{OCH}_{2} \mathrm{CH}_{2} \mathrm{OH}\right)$ is a side-product in the synthesis of cyanoamine $13 \mathbf{e}$ and presents as a possible precursor for ions 9 and 10. The product-ion spectrum of $[\mathbf{1 4 h}+\mathrm{H}]^{+}$shown in Figure 4 is similar to that of the respective guanosine analog [ $2 \mathrm{~h}$ $+\mathrm{H}]^{+}$of Figure 3; its fragmentation is described in Scheme 9 and relevant stationary structures are shown in Scheme 10.

The proton affinities of $\mathrm{H}_{2} \mathrm{~S}$ and $\mathrm{MeSH}$ are $744.8 \pm 10.0$ $\mathrm{kJ} / \mathrm{mol}$ [56] and $774.0 \pm 4.2 \mathrm{~kJ} / \mathrm{mol}$ [57], respectively. The computed affinities for S-protonation of $\mathbf{1 4 h}$ fall into this range (Table 2). As with guanine, N7-protonation is preferred and we discuss the fragmentation options of the N7-protonated ion 39 of $[14 \mathrm{~h}+\mathrm{H}]^{+}$. The major characteristics of the fragmentation of $[\mathbf{1 4 h}+\mathrm{H}]^{+}$and $[2 \mathbf{h}+\mathrm{H}]^{+}$are analogous.

The initially formed ion 39 occurs in the (Z)-conformation only and its conversion to $(Z) \mathbf{- 1 2 9}$ via transition-state structure 128 requires $\Delta H_{\text {act }}=250.5 \mathrm{~kJ} / \mathrm{mol}$. Once $(Z)-129$ is reached, its slightly more stable rotamer (Z)-129 also is easily accessible via rotational transition-state structure 130. The reaction $(E)-\mathbf{1 2 9} \rightarrow \mathbf{1 3 3 ^ { \ddagger }} \rightarrow(E)-\mathbf{1 3 4}$ requires an activation barrier of $\Delta H_{\text {act }}=194.8 \mathrm{~kJ} / \mathrm{mol}$ and (Z)-134 then becomes accessible by facile S-inversion. In the case of 132, (E)-132 is the only existing rotamer and it is formed by the reaction $(Z)-\mathbf{1 2 9} \rightarrow \mathbf{1 3 1}^{\ddagger} \rightarrow(E)$-132 with an activation barrier of $\Delta H_{\text {act }}=214.0 \mathrm{~kJ} / \mathrm{mol}$.

As with protonated guanine, we explored whether a ring-opened structure of type $\mathbf{1 3 5}$ might exist as a minimum, and it was found that such a structure 


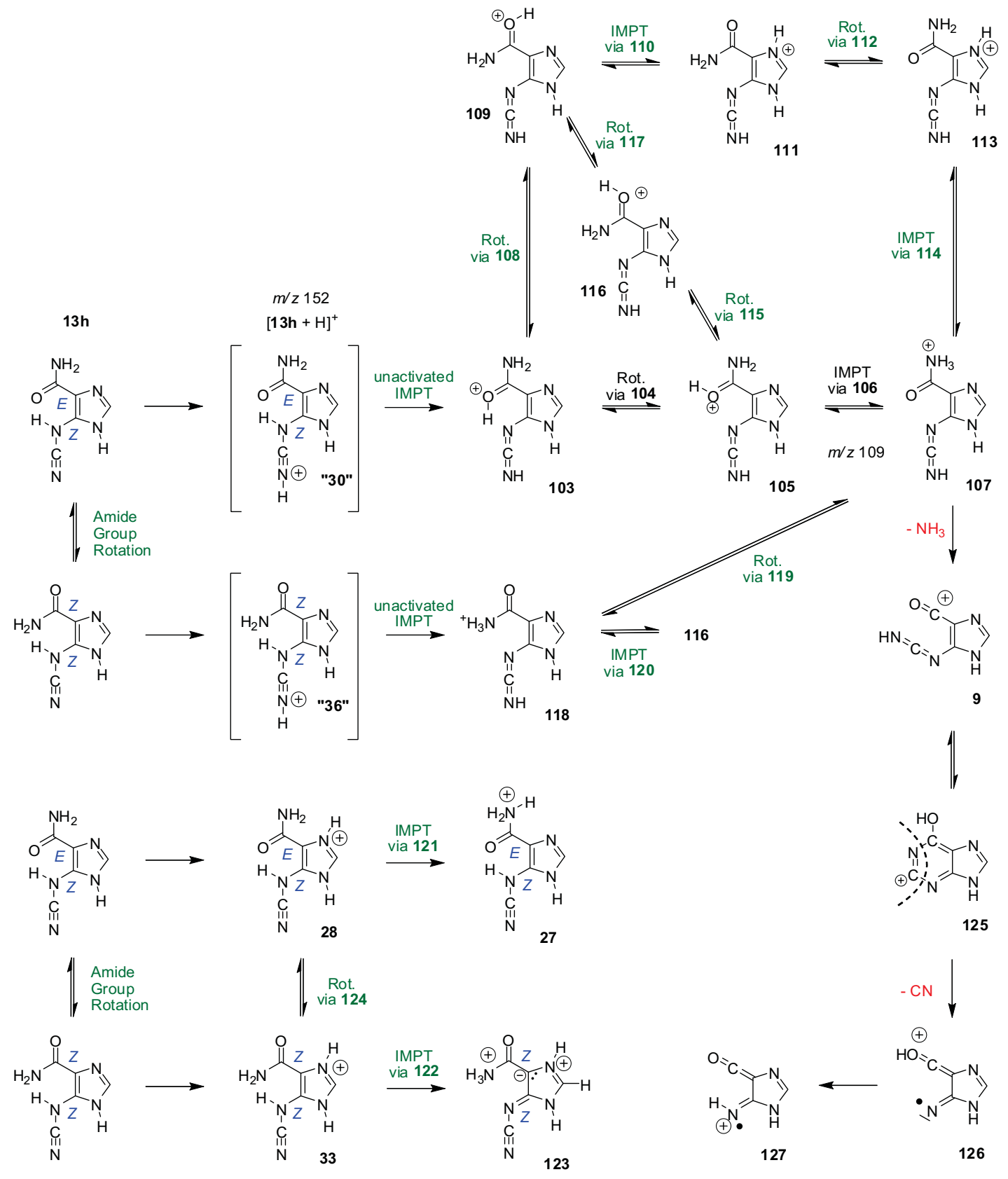

Scheme 8. Fragmentation of protonated 5-cyanoaminoimidazole-4-carboxamide $[13 \mathrm{~h}+\mathrm{H}]^{+}$.

serves as the transition-state structure for the formation of 136. The ascent to 135 requires $\Delta H_{\text {act }}=283.8$ $\mathrm{kJ} / \mathrm{mol}$ and significantly more activation than the formation of 129. It remains to be explored whether the PES region along the up-path to 135 offers entry points for methyl isothiocyanate expulsion. The above discussion of carbodiimide elimination from protonated guanine via transition-state structure 99 and leading to $\mathbf{1 0 0}$ (Scheme 6) applies in complete analogy to the formation of $\mathbf{1 0 0}$ via $\mathbf{1 3 7}$.

The computational analysis suggests that $\mathbf{1 3 4}$ is the precursor for MeSH elimination and, hence, ion [14h + $\mathrm{H}-\mathrm{MeSH}]^{+}$most likely leads to structure 9' via the least-energy path. Yet, structure $10^{\prime}$ cannot be dis- missed because every (Z)-129 formed contains enough energy to overcome any of the barriers along the paths to $\mathbf{9}^{\prime}$ or $\mathbf{1 0}$.

The discussions of the fragmentations of $[2 \mathbf{h}+\mathrm{H}]^{+}$ and $[13 \mathrm{~h}+\mathrm{H}]^{+}$(Schemes 6 and 8) suggest that the preference of $[2 \mathbf{h}+\mathrm{H}]^{+}$for $\mathrm{CO}$ elimination from 95 and the preference of $[\mathbf{1 3 h}+\mathrm{H}]^{+}$for $\mathrm{CN}$ elimination from 9 are consequences of the hydrogen pattern. The absence of CO loss in the fragmentation of [14h + $\mathrm{H}^{+}$shows that an $\mathrm{NH}$ in the proximity of the putative carbene site is not sufficient to enable decarbonylation. Decarbonylation only occurs from 95, the ion in which the proximate $\mathrm{NH}$ is part of the imidazolium system. 


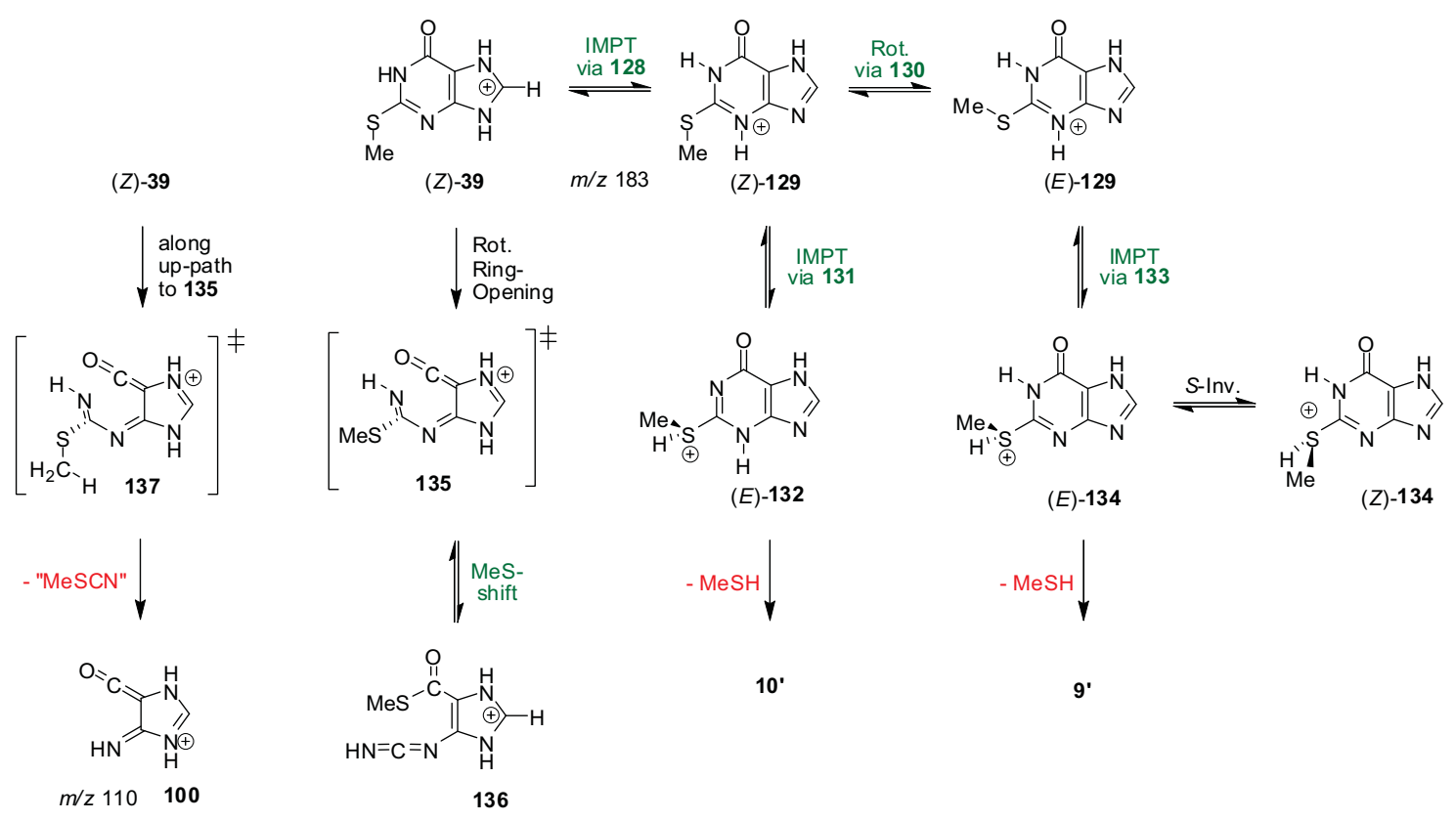

Scheme 9. Major fragmentation paths of protonated thioether $\mathbf{1 4 h}$.

\section{ESI-MS of Deoxycytidine}

The mass spectrum of electrosprayed deoxycytidine in Figure 1 shows two peaks: the quasi-molecular ion $[3 \mathbf{d}+\mathrm{H}]^{+}$and the fragment $[3 \mathbf{h}+\mathrm{H}]^{+}, m / z 112$, in which the sugar was replaced by hydrogen. The fragmentation of $[3 \mathbf{h}+\mathrm{H}]^{+}$was studied by MS/MS and the spectrum of Figure 5 is rationalized in Scheme 11õ with reference to the energies of the computed structures shown in Scheme 12.

The proton affinities show that amino group protonation cannot compete with protonation at the carbonyl-O or N3. With $\mathbf{5 0}$ present and/or accessible from $\mathbf{5 1}$ and $\mathbf{5 2}$, ammonium ion 48 becomes available via transition-state structure 138 with $\Delta H_{\text {act }}=227.1 \mathrm{~kJ} / \mathrm{mol}$. Ion 11h easily ring-opens to thermodynamically more stable $\mathbf{1 2 h}$, protonated (Z)-3-isocyanatoacrylonitrile [58].

We also considered options for $\mathrm{NH}_{3}$ elimination from ring-opened structures and three modes were considered for ring-opening, namely by way of C2-N3 cleavage and rotation of either the amidine unit via 139 or of the protonated isocyanato group via $\mathbf{1 4 1}$ as well as by way of N1-C2 cleavage and rotation of the protonated isocyanato group via 145. The activation enthalpies $\Delta H_{\text {act }}$ for the reactions $50 \rightarrow 139^{\ddagger} \rightarrow 140,50 \rightarrow 141^{\ddagger} \rightarrow 142 \rightarrow 143^{\ddagger}$ $\rightarrow \mathbf{1 4 4}$, and $\mathbf{5 0} \rightarrow \mathbf{1 4 5} 5^{\ddagger} \rightarrow \mathbf{1 4 6}$ are 352.0, 308.2, and 315.9 $\mathrm{kJ} / \mathrm{mol}$, respectively, and these energy requirement are too high to compete with the path via 48 (Table 3).

The strong peak with $\mathrm{m} / \mathrm{z} 69$ shows that protonated cytosine can eliminate isocyanic acid and our potential surface analyses provide information about possible paths for HNCO elimination. The stage is set for $\mathrm{HCNO}$ elimination once the $\mathrm{N}-\mathrm{C}$ bond of $\mathbf{5 0}$ is broken along any of the up-paths that lead to the transitionstate structures 139, 141, and 145. Actual elimination might occur within wide ranges of the up-paths and well before the respective transition-state region for rotation would be reached. This scenario for $\mathrm{HNCO}$ elimination from 50 is related to the eliminations of $\mathrm{CN}_{2} \mathrm{H}_{2}$ from 23 and of MeSCN from 39, but it is much less complicated. Only one more $\mathrm{CN}$ cleavage has to
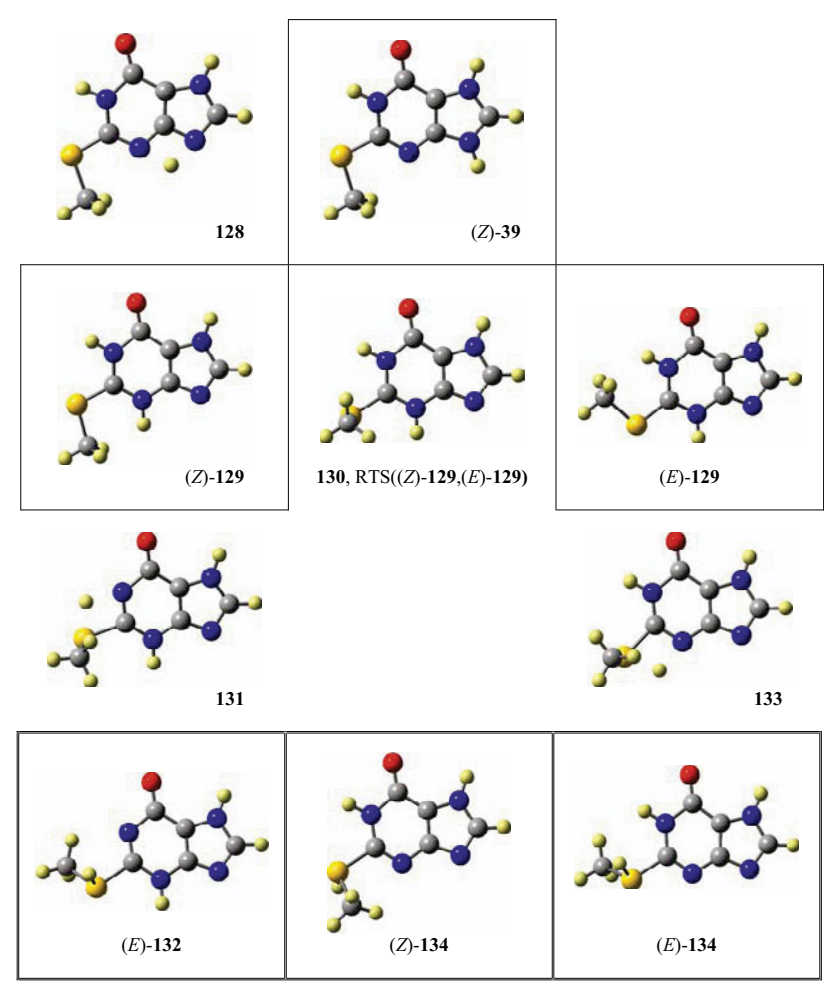

Scheme 10. Paths to sulfonium ions (double-lined) from the conjugate acids of $\mathbf{1 4 h}$. 
deoxycytidine_040323162403\#1-150 RT: 0.00-1.27 AV: 150 NL: $6.36 \mathrm{E} 5$

T: + c ESI sid=30.00 ms2112.00@-80.00 [19.99-120.02]

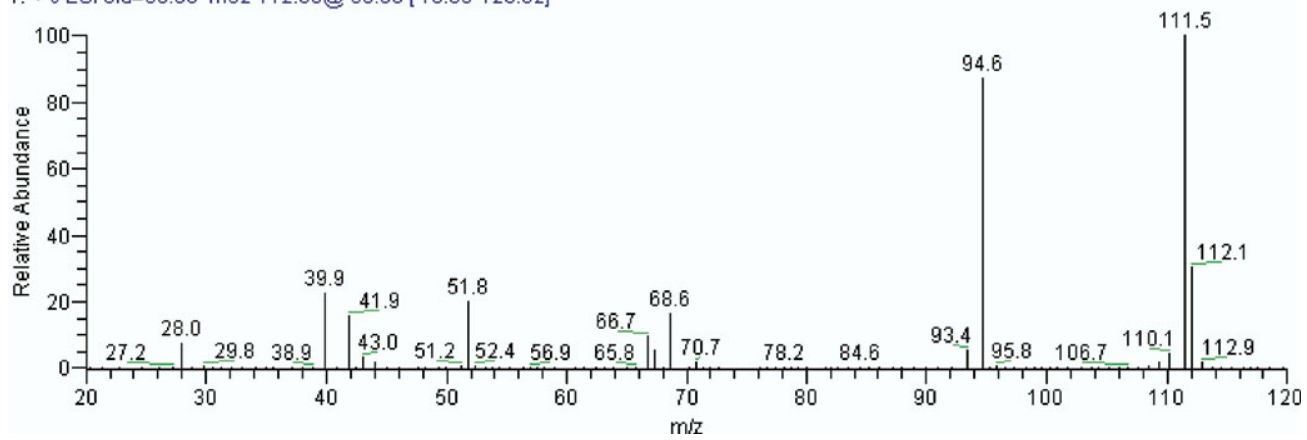

Figure 5. Product-ion spectrum of $[\mathbf{1 2} \mathbf{h}+\mathrm{H}]^{+}, m / z \mathbf{1 1 2}$, produced by in-source fragmentation of protonated deoxycytidine.

occur (no additional proton transfer) and 2D-scans ( $\mathrm{C}-\mathrm{N}$ rotational coordinate and $\mathrm{C}-\mathrm{N}$ bond length) and/or dynamics studies could provide any desired level of mechanistic detail. Considering the energies of the rotational transition-state structures and basic principles of potential energy surface analysis, the up-paths to 141 and 145 appear most suited and these paths also provide consistent rationales for the results of the MS experiments. The elimination of $\mathrm{H}-\mathrm{N} 3=\mathrm{C}=\mathrm{O}$ along the up-path to 145 would lead to 147 and explain the

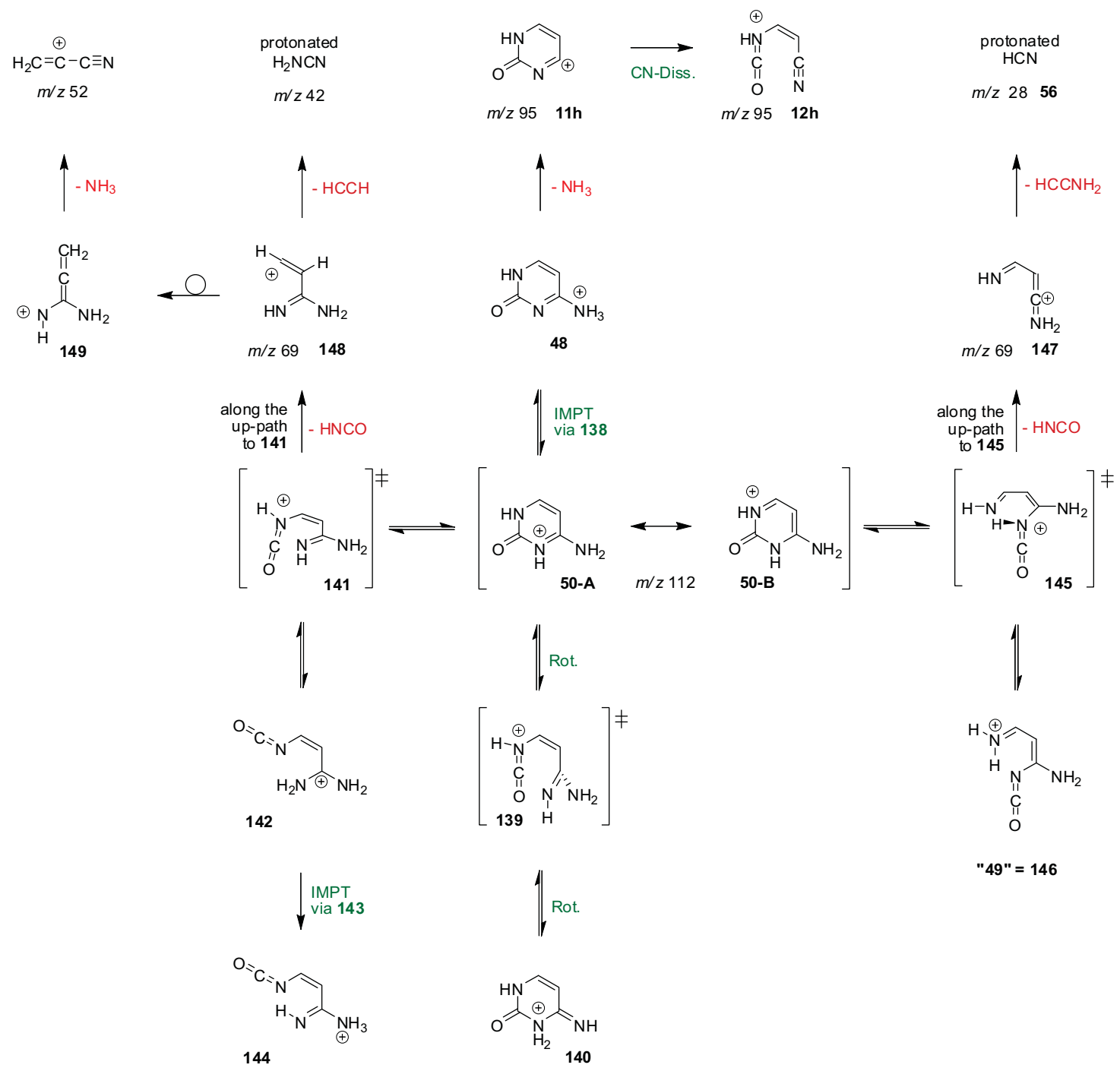

Scheme 11. Major fragmentation paths of protonated cytosine. 

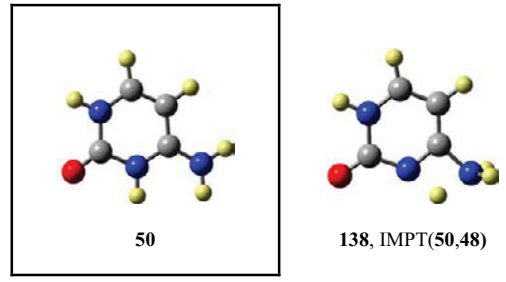

138, IMPT $(50,48)$
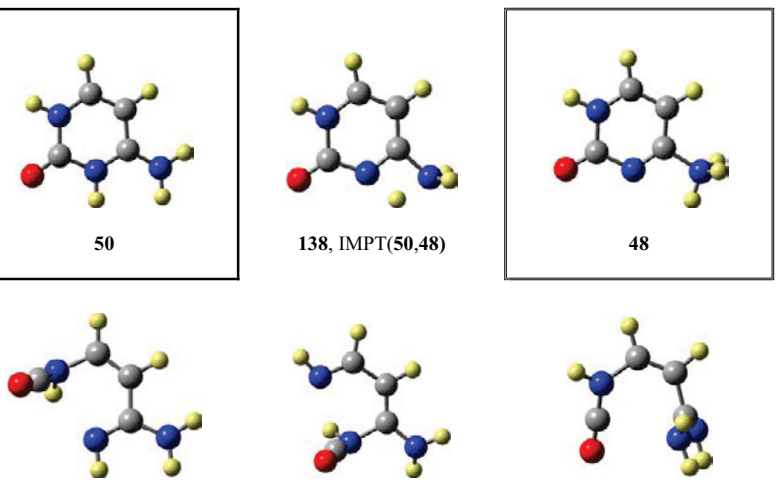

$141, \operatorname{RTS}(50,142)$

$145, \operatorname{RTS}(50,146)$
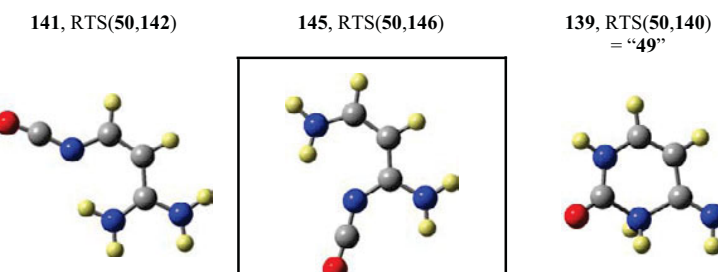

142
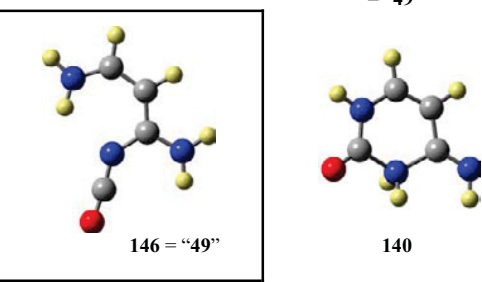

140

Scheme 12. The N3-protonated cytosine 50 (single-lined) leads to $\mathrm{NH}_{3}$ elimination from $[3 \mathrm{~h}+\mathrm{H}]^{+}$via ammonium ion 48 (double-lined). Paths involving CN cleavage and rotation via 139, 141, and 145 also have been explored. formation of protonated HCN, $56(\mathrm{~m} / \mathrm{z} 28)$. The elimination of $\mathrm{H}-\mathrm{N} 1=\mathrm{C}=\mathrm{O}$ along the up-path to 141 would lead to 148 instead and subsequent loss of acetylene would result in protonated cyanamide $(\mathrm{m} / \mathrm{z} 42)$. Alternatively, this mode of HNCO elimination might be followed by 1,2-H-shift to 148 and $\mathrm{NH}_{3}$ elimination to protonated cyanoacetylene $(\mathrm{m} / \mathrm{z} 52)$.

The study of the fragmentation of 1,3 -double ${ }^{15} \mathrm{~N}$ labeled cytidines by Wang et al. [35] revealed the important new finding that $\mathrm{NH}_{3}$ eliminated from $[3 \mathrm{~h}+$ $\mathrm{H}]^{+}$may contain ${ }^{14} \mathrm{~N}$ or ${ }^{15} \mathrm{~N}$. The exchange of the N3and amino- $\mathrm{N}$ atoms was rationalized by the Dimroth rearrangement $\mathbf{5 0} \rightleftarrows \mathbf{1 4 0}$ via $\mathrm{C} 2-\mathrm{N} 3$ cleavage and $\mathbf{1 3 9} 9^{\ddagger}$ and subsequent proton transfer to reform 50. To explain the observed excess of unlabeled $\mathrm{NH}_{3}$ a "small fraction" of the elimination had to be generated by the path $\mathbf{5 0} \rightarrow$ 48 and, hence, that path was thought to compete with the Dimroth rearrangement. While this explanation was perfectly reasonable, the computed activation barriers indicate however a very clear advantage for the path $50 \rightarrow 48$ over the Dimroth rearrangement. Tureček et al. initially considered only N1-C2 cleavage for $[3 \mathrm{~h}+\mathrm{H}]^{+}$ and the rearrangement $50 \rightleftarrows \mathbf{1 4 6}$ via $145^{\ddagger}$ to explain the HNCO elimination [34a]. The labeling results required a reassessment and Tureček et al. [34b] now argued for the rearrangement $\mathbf{5 0} \rightleftarrows \mathbf{1 4 2}$ via $\mathbf{1 4 1}^{\ddagger}$ and $\mathrm{NH}_{3}$ elimination from 144. In fact, the authors argued for the

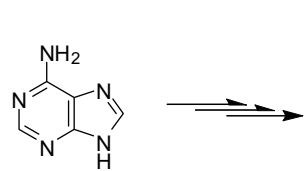

$1 \mathrm{~h}$<smiles></smiles><smiles>Cc1ccccc1</smiles>

$2 \mathrm{~h}$

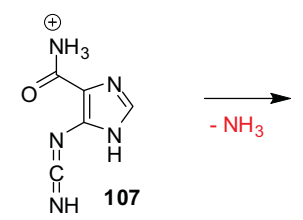<smiles></smiles>

87

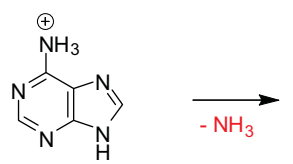

15

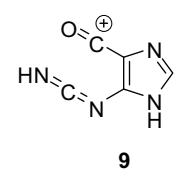

$\mathrm{N}^{\mathrm{O}}$

95
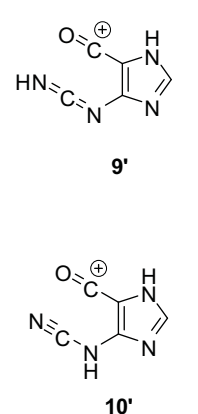

$\longleftarrow$ - MeSH

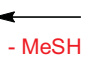<smiles>CSc1nc2[nH]cnc2c(=O)[nH]1</smiles>

$14 \mathrm{~h}$
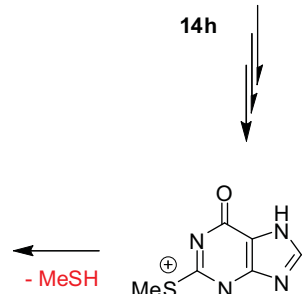<smiles>CSc1nc(=O)c2[nH]cnc2[nH]1</smiles>

132

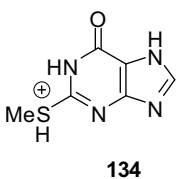

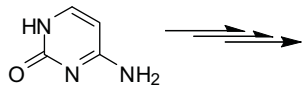

3h

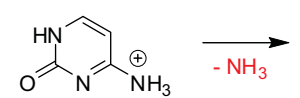

48

Scheme 13. Summary of results. 
exclusive elimination of ammonia from the ring-opened structure $\mathbf{1 4 4}$ and noted that ammonia loss from $\mathbf{4 8}$ is endothermic. Yet, one cannot ignore the fact that $\Delta H_{\text {act }}(\mathbf{5 0} \rightarrow \mathbf{4 8})$ is much smaller than $\Delta H_{\text {act }}(\mathbf{5 0} \rightarrow \mathbf{1 4 1})$, that $\mathrm{NH}_{3}$ elimination from 48 will occur in the mass spectrometer, and that the ammonia elimination is essentially irreversible under those conditions.

To resolve this paradoxical situation requires the accessibility of a mechanism for ammonia elimination that can compete with the reaction $50 \rightarrow 48$ and that accounts for the N-scrambling. We have pointed out that the stage is set for HCNO elimination as soon as one of the $\mathrm{N}-\mathrm{C}$ bonds of $\mathbf{5 0}$ is broken along any of the up-paths leading to the transition state structures $139^{\ddagger}$, $141^{\ddagger}$, and $145^{\ddagger}$ and that the actual elimination might occur within wide ranges of the up-paths and well before the respective transition state region for rotation would be reached. This means that the structural possibilities for $[3 \mathbf{h}+\mathrm{H}]^{+}$are not described in a comprehensive fashion by the conventional consideration of sequences of elemental steps. For example, ion 144 can be formed via intermediate $\mathbf{1 4 2}$ in the sequence outlined in Scheme 11, but this option does not exclude the possibility of formation of $\mathbf{1 4 4}$ directly from $\mathbf{5 0}$ via trajectories that do not pass through 142. To allow for these possible trajectories is not expected to result in any conceptional difference for the outcomes of the reaction of 50 to 146 and/or 147, for the Dimroth rearrangement of 50 , or for the reaction of 50 to $\mathbf{1 4 4}$. On the other hand, to consider such trajectories does reveal an interesting alternative for the product palette produced by "the path" from 50 to 149 . There is the obvious possibility that the $\mathrm{HNCO}$ and $\mathrm{NH}_{3}$ eliminations occur in sequence. And one can consider the additional scenario in which intramolecular proton transfer and $\mathrm{NH}_{3}$ elimination occur after N1-C2 cleavage but before $\mathrm{HNCO}$ elimination. This region of the potential energy surface of $[3 \mathrm{~h}+\mathrm{H}]^{+}$includes structures resulting by N1-C2 cleavage (without the simultaneous rotations leading toward structures of types 139 or 141) and it also includes ion-molecule complexes formed by $\mathbf{1 4 8}$ and HNCO. Our analysis suggests, for example, that the acyclic structure $\mathbf{2 3}$ discussed in [34b] to explain $\mathrm{CO}$ and $\mathrm{HNCO}$ eliminations might play a role in $\mathrm{NH}_{3}$ elimination as well.

\section{Conclusion}

MS experiments are rather sensitive to instrument settings (Table 1) and significant quantitative differences in fragmentation modes may occur from one experiment to the next. Nevertheless, our study shows that the protonated nucleobases $[\mathbf{1 h}+\mathrm{H}]^{+},[2 \mathbf{h}+\mathrm{H}]^{+}$, and $[3 \mathrm{~h}+\mathrm{H}]^{+}$can be observed by ESI-MS and that their modes of initial fragmentation can be understood with the knowledge of the tautomer stabilities and the consideration of the paths for intramolecular proton migration. It is for this understanding, that we have confidence in the completeness of our study and we contend that we have observed all of the main modes of initial fragmentation.

We discussed ions $\mathbf{8 - 1 0}$ and $\mathbf{1 2}$ as possible reactive intermediates in nitrosative deamination chemistry in solution and it has been our aim to provide more direct experimental evidence for the existence of these ions. Hence, we studied $\mathrm{NH}_{3}$ elimination from the conjugate acids of the nucleobases $1 \mathrm{~h}-3 \mathrm{~h}$ and models $13 \mathrm{~h}$ and $14 \mathrm{~h}$, and the key results are summarized in Scheme 13. Everyone of the postulated ions either was found to exist in the gas phase or to exist in the gas phase as a tautomer. These results provide "semi-direct" experimental evidence for the existence of these ions. The new data go well beyond the "indirect evidence" stemming from inference from mechanistic studies and the additional structural characterization in the MS experiment [59] could provide for "direct" evidence.

The amino group hardly ever is the best protonation site of the substrate, and we discussed possible mechanisms for $\mathrm{NH}_{3}$ elimination that feature the amino group as the dissociative protonation site. The hydrogen migration is facilitated by electrophilic catalysis, and the standard Lewis structure might obscure the propensity of a hydrogen atom to migration (i.e., 63, 23, 50). Examples have been provided for cases in which the acidic $\mathrm{H}$ and the $\mathrm{NH}_{2}$-group are in a 1,2-relation $(16,21,22,23,50,63,68,81,105,142)$, a 1,3 -relation $(\mathbf{1 7}, \mathbf{2 8}, \mathbf{7 7}, \mathbf{1 1 3})$, or a 1,5 -relation $(\mathbf{6 5}$, " 30, , "36," 33). This kind of electrophilic catalysis also facilitates the elimination of $\mathrm{H}_{2} \mathrm{NCN}$ from 23 and of $\mathrm{MeSH}$ and MeSCN from 39.

\section{Acknowledgments}

This study was supported by the United States National Institutes of Health (GM61027). MU Research Support Computing was made possible by Federal Earmark NASA Funds for Bioinformatics Consortium Equipment and additional financial support from Dell, SGI, Sun Microsystems, TimeLogic, and Intel.

\section{References}

1. (a) Geiduschek, E. P. Reversible Denaturation of Deoxyribonucleic Acid (DNA). Proc. Natl. Acad. Sci. U.S.A. 1961, 47, 950-955. (b) Geiduschek, E. P. On the Factors Controlling the Reversibility of DNA Denaturation. J. Mol. Biol. 1962, 4, 467-487.

2. Caulfield, J. L.; Wishnok, J. S.; Tannenbaum, S. R. Nitric Oxide-Induced Interstrand Cross-Links in DNA. Chem. Res. Toxicol. 2003, 16, 571-574.

3. Committee on Nitrite and Alternative Curing Agents in Food. The Health Effect of Nitrate, Nitrite, and N-Nitroso Compounds; National Academy Press: Washington, D.C., 1981.

4. Furia, T. E. Handbook of Food Additives, 2nd ed.; CRC Press: Cleveland, 1972; pp 150-155.

5. Wakabayashi, K. In Mutation and the Environment, Part E; Albertini, R. J.; Ed.; Wiley-Liss, Inc.: New York, 1990; pp 107-116.

6. Culotta, E.; Koshland, D. E. No News is Good News. Science 1992, 258, 1862-1865.

7. Marnett, L. J. Nitric Oxide: Chemical Events in Toxicity. Chem. Res. Toxicol. 1996, 9, 807-808.

8. Davis, K. L.; Martin, E.; Turko, I. V.; Murad, F. Novel Effects of Nitric Oxide. Annu. Rev. Pharmacol. Toxicol. 2001, 41, 203-236.

9. Jackson, A. L.; Loeb, L. A. The Contribution of Endogenous Sources of DNA Damage to the Multiple Mutations in Cancer. Mutat. Res. 2001, $477,7-21$

10. Ohshima, H.; Bartsch, H. Chronic Infections and Inflammatory Processes as Cancer Risk Factors: Possible Role of Nitric Oxide in Carcinogenesis. Mutat. Res. 1994, 305, 253-264. 
11. Tamir, S.; Tannenbaum, S. R.The Role of Nitric Oxide (NO) in the Carcinogenic Process.Biochim. Biophys. Acta 1996, 1288, F31-F36.

12. Suzuki, T.; Ide, H.; Yamada, M.; Endo, N.; Kanaori, K.; Tajima, K.; Morii, T.; Makino, K. Formation of 2'-Deoxyoxanosine from 2'-Deoxyguanosine and Nitrous Acid: Mechanism and Intermediates. Nucleic Acids Res 2000, 28, 544-551.

13. Lucas, L. T.; Gatehouse, D.; Shuker, D. E. G. Efficient Nitroso Group Transfer from N-Nitrosoindoles to Nucleotides and 2'-Deoxyguanosine at Physiological pH. A New Pathway for N-Nitroso Compounds to Exert Genotoxicity. J. Biol. Chem. 1999, 274, 18319-18326.

14. Dong, M.; Wang, C.; Deen, W. M.; Dedon, P. C. Absence of 2'Deoxyoxanosine and Presence of Abasic Sites in DNA Exposed to Nitric Oxide at Controlled Physiological Concentrations. Chem. Res. Toxicol. 2003, 16, 1044-1055

15. Glaser, R.; Son, M.-S. Pyrimidine Ring Opening in the Unimolecular Dediazoniation of Guanine Diazonium Ion. An ab Initio Theoretical Study of the Mechanism of Nitrosative Guanosine Deamination. J. Am. Chem. Soc. 1996, 118, 10942-10943.

16. Glaser, R.; Rayat, S.; Lewis, M.; Son, M.-S.; Meyer, S. Theoretical Studies of DNA Base Deamination. 2. Ab Initio Study of DNA Base Diazonium Ions and of Their Linear, Unimolecular Dediazoniation Paths. J. Am. Chem. Soc. 1999, 121, 6108-6119.

17. Glaser, R.; Lewis, M. Single- and Double-Proton-Transfer in the Aggregate Between Cytosine and Guaninediazonium Ion. Org. Lett. 1999, 1, 273-276.

18. Glaser, R.; Wu, H.; Lewis, M. Cytosine Catalysis of Nitrosative Guanine Deamination and Interstrand Cross-Link Formation. J. Am. Chem. Soc. 2005, 127, 7346-7358.

19. Rayat, S.; Glaser, R. 5-Cyanoimino-4-Oxomethylene-dihydroimidazole and Nitrosative Guanine Deamination. A Theoretical Study of Geometries, Electronic Structures, and N-Protonation. J. Org. Chem. 2003, 68, 9882-9892.

20. Rayat, S.; Majumdar, P.; Tipton, P.; Glaser, R. 5-Cyanoimino-4-Oxomethylene4,5-Dihydroimidazole and 5-Cyanoamino-4-Imidazolecarboxylic Acid Intermediates in Nitrosative Guanosine Deamination. Evidence from (18)OLabeling Experiments. J. Am. Chem. Soc. 2004, 126, 9960-9969.

21. Qian, M.; Glaser, R. 5-Cyanoamino-4-Imidazolecarboxamide and Nitrosative Guanine Deamination: Experimental Evidence for Pyrimidine Ring-Opening During Deamination. J. Am. Chem. Soc. 2004, 126, $2274-$ 2275.

22. Qian, M.; Glaser, R. Demonstration of an Alternative Mechanism for G-to-G Cross-Link Formation. J. Am. Chem. Soc. 2005, 127, 880-887.

23. Hodgen, B.; Rayat, S.; Glaser, R. Nitrosative Adenine Deamination: Facile Pyrimidine Ring-Opening in the Dediazoniation of Adeninediazonium Ion. Org. Lett. 2003, 5, 4077-4080.

24. Shuo Yang. Ammonia Elimination from Protonated Nucleobases. Proton Mobility, Ammonium Ion Formation, and Fragmentation Paths; M.S. Dissertation, University of Missouri-Columbia, 2007.

25. McLafferty, F. W.; Wachs, T.; Koppel, C.; Dymerski, P. P.; Bockhoff, F. M. Advances in Mass Spectrometry, Vol. VIIb; Daly, N. R., Ed.; Institute of Petroleum: London, 1978, p. 109.

26. (a) Koch, W.; Holthausen, M. C. A Chemist's Guide to Density Functional Theory, 2nd ed.; Wiley-VCH: Weinheim, 2001. (b) Parr, R. G; Weitao, Y. Density-Functional Theory of Atoms and Molecules; International Series of Monographs on Chemistry. Oxford University Press: Oxford, UK, 1994.

27. Frisch, M. J.; Trucks, G. W.; Schlegel, H. B.; Scuseria, G. E.; Robb, M. A.; Cheeseman, J. R.; Montgomery, J. A., Jr.; Vreven, T.; Kudin, K. N.; Burant, J. C.; Millam, J. M.; Iyengar, S. S.; Tomasi, J.; Barone, V.; Mennucci, B.; Cossi, M.; Scalmani, G.; Rega, N.; Petersson, G. A.; Nakatsuji, H.; Hada, M.; Ehara, M.; Toyota, K.; Fukuda, R.; Hasegawa, J.; Ishida, M.; Nakajima, T.; Honda, Y.; Kitao, O.; Nakai, H.; Klene, M.; Li, X.; Knox, J. E.; Hratchian, H. P.; Cross, J. B.; Bakken, V.; Adamo, C.; Jaramillo, J.; Gomperts, R.; Stratmann, R. E.; Yazyev, O.; Austin, A. J.; Cammi, R.; Pomelli, C.; Ochterski, J. W.; Ayala, P. Y.; Morokuma, K.; Voth, G. A.; Salvador, P.; Dannenberg, J. J.; Zakrzewski, V. G.; Dapprich, S.; Daniels, A. D.; Strain, M. C.; Farkas, O.; Malick, D. K.; Rabuck, A. D.; Raghavachari, K.; Foresman, J. B.; Ortiz, J. V.; Cui, Q.; Baboul, A. G.; Clifford, S.; Cioslowski, J.; Stefanov, B. B.; Liu, G.; Liashenko, A.; Piskorz, P.; Komaromi, I.; Martin, R. L.; Fox, D. J.; Keith, T.; Al-Laham, M. A.; Peng, C. Y.; Nanayakkara, A.; Challacombe, M.; Gill, P. M. W.; Johnson, B.; Chen, W.; Wong, M. W.; Gonzalez, C.; and Pople, J. A. Gaussian 03, Revision D. 01; Gaussian, Inc.: Wallingford CT, 2004

28. Rice, J. M.; Dudek, G. O. Mass Spectra of Nucleic Acid Derivatives. II. Guanine, Adenine, and Related Compounds. J. Am. Chem. Soc. 1967, 89, 2719-2725.

29. Barrio, M. C. G.; Scopes, D. I. C.; Holtwick, J. B.; Leonard, N. J. Syntheses of all Singly Labeled [15N]-Adenines: Mass Spectral Fragmentation of Adenine. Proc. Natl. Acad. Sci. U.S.A. 1981, 78, 3986-3988.

30. Sethi, S. K.; Gupta, S. P.; Jenkins, E. E.; Whitehead, C. W.; Townsend, L. B.; McCloskey, J. A. Mass Spectrometry of Nucleic Acid Constituents. Electron Ionization Spectra of Selectively Labeled Adenines. J. Am. Chem. Soc. 1982, 104, 3349-3353.

31. Rice, J. M.; Dudek, G. O.; Barber, M. Mass Spectra of Nucleic Acid Derivatives Pyrimidines. J. Am. Chem. Soc. 1965, 87, 4569-4576.

32. Fryèák, P.; HušKová, R.; Tomáš, A.; Lemr, K. Atmospheric Pressure Ionization Mass Spectrometry of Purine and Pyrimidine Markers of Inherited Metabolic Disorders. J. Mass Spectrom. 2002, 37, 1242-1248.

33a. Wilson, M. S.; McCloskey, J. A. Chemical ionization mass spectrometry of nucleosides. Mechanisms of ion formation and estimations of proton affinity. J. Am. Chem. Soc. 1975, 97, 3436-3444. 33b. Nelson, C. C.; McCloskey, J. A. Collision-Induced Dissociation of Adenine. J. Am. Chem. Soc. 1992, 114, 3661-3668.

33c. Gregson, J. M.; McCloskey, J. A. Collision-Induced Dissociation of Protonated Guanine. Int. J. Mass Spectrom. Ion Processes 1997, 165/166, 475-485.

34a. Yao, C.; Cuadrado-Peinado, M. L.; Polasek, M.; Tureček, F. Gas-phase tautomers of protonated 1-methylcytosine. Preparation, energetics, and dissociation mechanisms. J. Mass Spectrom. 2005, 40, 1417-1428.

34b. Yao, C.; Tureček, F.; Polce, M. J.; Wesdemiotis, C. Proton and hydrogen atom adducts to cytosine. An experimental and computational study. Int. J. Mass Spectrom. 2007, 265, 106-123.

35. Cao, H.; Wang, Y. Collisionally Activated Dissociation of Protonated 2'-Deoxycytidine, 2'-Deoxyuridine, and their Oxidatively Damaged Derivatives. J. Am. Soc. Mass. Spectrom. 2006, 17, 1335-1341.

36. Tureček, F.; Chen, X. Protonated Adenine: Tautomers, Solvated Clusters, and Dissociation Mechanisms. J. Am. Soc. Mass Spectrom. 2005, 16, 1713-1726.

37. Curtiss, L. A.; Redfern, P. C.; Frurip, D. J. Theoretical Methods for Computing Enthalpies of Formation of Gaseous Compounds. Rev. Comput. Chem. 2000, 15, 147-211.

38. Giese, B.; McNaughton, D. Density Functional Theoretical (DFT) and Surface-Enhanced Raman Spectroscopic Study of Guanine and Its Alkylated Derivatives. Part 1. DFT Calculations on Neutral, Protonated, and Deprotonated Guanine. Phys. Chem. Chem. Phys. 2002, 4, 5161-5170.

39. Jang, Y. H.; Goddard, W. A., III; Noyes, K. T.; Sowers, L. C.; Hwang, S. Chung, D. S. pK Values of Guanine in Water: Density Functional Theory Calculations Combined with Poisson-Boltzmann ContinuumSolvation Model. J. Phys. Chem. B 2003, 107, 344-357.

40. Greco, F.; Liguori, A.; Sindona, G.; Uccella, N. Gas-Phase Proton Affinity of Deoxyribonucleosides and Related Nucleobases by Fast Atom Bombardment Tandem Mass Spectrometry. J. Am. Chem. Soc. 1990, 112, 9092-9096.

41. Chandra, A. K.; Nguyen, M. T.; Uchimaru, T.; Zeegers-Huyskens, T. Protonation and Deprotonation Enthalpies of Guanine and Adenine and Implications for the Structure and Energy of Their Complexes with Water: Comparison with Uracil, Thymine, and Cytosine. J. Phys. Chem. A 1999, 103, 8853-8860.

42. Taft, R. W. Proton Transfer Reaction; Caldin, E. F., Gold, V., Eds.; Wiley-Halstead: New York, 1975; Chap II

43. Lias, S. G.; Bartmess, J. E.; Liebman, J. F.; Holmes, J. L.; Levin, R. D.; Mallard, W. G. Gas-Phase Ion and Neutral Thermochemistry. J. Phys. Chem. Ref. Data 1988, (Suppl. 1), 17.

44. Karpas, Z.; Berant, Z.; Stimac, R. M. An Ion Mobility Spectrometry/ Mass Spectrometry (IMS/MS) Study of the Site of Protonation in Anilines. Struct. Chem. 1990, 1, 201-204.

45. Flammang, R.; Dechamps, N.; Pascal, L.; Van Haverbeke, Y.; Gerbaux, P.; Nam, P.-C.; Nguyen, M. T. Ring Versus Nitrogen Protonation of Anilines. Lett. Org. Chem. 2004, 1, 23-30.

46. Tu, Y.-P. Dissociative Protonation Sites: Reactive Centers in Protonated Molecules Leading to Fragmentation in Mass Spectrometry. J. Org. Chem. 2006, 71, 5482-5488.

47. Paizs, B.; Suhai, S. Fragmentation Pathways of Protonated Peptides. Mass Spectrom. Rev. 2005, 24, 508-548.

48. Mouls, L.; Subra, G.; Aubagnac, J.-L.; Martinez, J.; Enjalbal, C. Tandem Mass Spectrometry of Amidated Peptides. J. Mass Spectrom. 2006, 41, 1470-1483.

49. Csonka, I. P.; Paizs, B.; Suhai, S. Modeling of the Gas-Phase Ion Chemistry of Protonated Arginine. J. Mass Spectrom. 2004, 39, 1025-1035.

50. Cooper, T.; Talaty, E.; Grove, J.; Van Stipdonk, M.; Suhai, S.; Paizs, B. Isotope Labeling and Theoretical Study of the Formation of a3* Ions from Protonated Tetraglycine. J. Am. Soc. Mass Spectrom. 2006, 17, 1654-1664.

51. Glaser, R.; Hodgen, B.; Farrelly, D.; McKee, E. Adenine Synthesis in Interstellar Space: Mechanisms of Prebiotic Pyrimidine Ring-Formation in Monocyclic HCN-Pentamers. Astrobiology 2007, 7, 455-470.

52. Morgan, K. M. Reaction mechanisms. Part III. Pericyclic reactions Annu. Rep. Prog. Chem. B 2005, 101, 284-304.

53. Tordini, F.; Bencini, A.; Bruschi, M.; Gioai, L. D.; Zampella, G.; Fantucci, P. Theoretical Study of Hydration of Cyanamide and Carbodiimide. J. Phys. Chem. A 2003, 107, 1188-1196.

54. Polce, M. J.; Kim, Y.; Wesdemiotis, C. First Experimental Characterization of Aminocarbene. Int. J. Mass Spectrom. Ion Processes 1997, 167/168, 309-315.

55. Lin, H. Y.; Ridge, D. P.; Uggerud, E.; Vulpius, T. Unimolecular Chemistry of Protonated Formamide. Mass Spectrometry and ab Initio Quantum Chemical Calculations. J. Am. Chem. Soc. 1994, 116, 2996-3004.

56. Marynick, D. S.; Scanion, K.; Eades, R. A.; Dixon, D. A. Absolute Proton Affinities of $\mathrm{PH}_{3}$ and $\mathrm{H}_{2}$ S. J. Phys. Chem. 1981, 85, 3364-3366.

57. Haney, M. A.; Franklin, J. L. Mass Spectrometric Determination of the Proton Affinities of Various Molecules. J. Phys. Chem. 1969, 73, 4328 4331.

58. Glaser, R.; Wu, H.; von Saint Paul, F. Chemical Carcinogens in Nonenzymatic Cytosine Deamination: 3-Isocyanatoacrylonitrile. J. Mol. Model. 2006, 12, 731-737.

59. Cooper, H. J.; Hakansson, K.; Marshall, A. G. The Role of Electron Capture Dissociation in Biomolecular Analysis. Mass Spectrom. Rev. 2005, 24, 201-222. 